\section{Northwest Africa 5790: Revisiting Nakhlite Petrogenesis.}

A. Jambon*1, 4, V. Sautter 2 , J-A Barrat ${ }^{3}$, J. Gattacceca 5 , P. Rochette 5 , O. Boudouma1, 4, D. Badia 1, 4, B. Devouard 5, 6

1: Sorbonne Universités, UPMC Univ Paris 06, UMR 7193, Institut des Sciences de la Terre Paris (iSTeP), F-75005 Paris, France. albert.jambon@upmc.fr 2 : Museum National d'Histoire Naturelle and UPMC Univ Paris 06, IMPMC, UMR7590 75005 Paris, France. vsautter@mnhn.fr

3 : Université de Brest, CNRS UMR 6538 (Domaines Océaniques), I.U.E.M., Place Nicolas Copernic, 29280 Plouzané, France. barrat@univ-brest.fr 4. CNRS, UMR 7193, Institut des Sciences de la Terre Paris (iSTeP), F-75005 Paris, France 5 : Aix-Marseille Université, CNRS, CEREGE UM 34, F-13545 Aix-en-Provence cedex 4, France. gattacceca@cerege.fr 6 : Université Blaise Pascal, CNRS, Laboratoire Magmas et Volcans UMR 6524, 5 rue Kessler, F-63000 Clermont-Ferrand, France

* Corresponding author 


\section{ABSTRACT}

Northwest Africa 5790, the latest nakhlite find, is composed of 58 vol. \% augite, $6 \%$ olivine and $36 \%$ vitrophyric intercumulus material. Its petrology is comparable to previously discovered nakhlites but with key differences: (1) Augite cores display an unusual zoning between Mg\# 54 and 60; (2) Olivine macrocrysts have a primary Fe-rich core composition $(\mathrm{Mg} \#=35)$; (3) the modal proportion of mesostasis is the highest ever described in a nakhlite; (4) It is the most magnetite-rich nakhlite, together with MIL 03346, and exhibits the least anisotropic fabric. Complex primary zoning in cumulus augite indicates resorption due to complex processes such as remobilization of former cumulates in a new magma batch. Textural relationships indicate unambiguously that olivine was growing around resorbed augite, and that olivine growth was continuous while pyroxene growth resumed at a final stage. Olivine core compositions $(\mathrm{Mg} \#=35)$ are out of equilibrium with the augite core compositions (Mg\# 60-63) and with the previously inferred nakhlite parental magma $(\mathrm{Mg} \#=29)$. The presence of oscillatory zoning in olivine and augite precludes subsolidus diffusion that could have modified olivine compositions. NWA 5790 evidences at least two magma batches before eruption, with the implication that melt in equilibrium with augite cores was never in contact with olivine. Iddingsite is absent.

Accordingly, the previous scenarios for nakhlite petrogenesis must be revised. The first primary parent magmas of nakhlites generated varied augite cumulates at depth $(\mathrm{Mg} \#$ 66 to 60 ) as they differentiated to different extents. A subsequent more evolved magma batch entrained accumulated augite crystals to the surface where they were partly resorbed while olivine crystallized. Trace element variations indicate unambiguously that they represent consanguineous but different magma batches. The compositional differences among the various nakhlites suggest a number of successive lava flows. To 
65 account for all observations we propose a petrogenetic model for nakhlites based on 66 several (at least three) thick flows. Although NWA5790 belongs to the very top of one 67 flow, it should come from the lowest flow sampled, based on the lack of iddingsite. 


\section{INTRODUCTION}

As of January 2016 there are 162 recorded Martian meteorites, the so-called SNC (S for Shergottites, $\mathrm{N}$ for Nakhlites and $\mathrm{C}$ for Chassignites), plus a few non-SNC (see Meteoritical Bulletin database). Among those, the nakhlites represent only 7 meteorites (MIL 03346, NWA 817, Y-000593, Nakhla, Governador Valadares, Lafayette and NWA 998); Northwest Africa (NWA) 5790 and pairs thereof. NWA 5790 was found in the Sahara by nomads and purchased in Erfoud (Morocco) in 2010. The seven previously described nakhlites share a number of common features, such as their crystallization and cosmic ray exposure ages (1.3-1.4 Ga and $11 \pm 1.5 \mathrm{Ma}$ respectively, Nyquist et al. 2001). They are all olivine-bearing clinopyroxenites with a cumulate texture defined by coarse augite and olivine crystals set in a fine-grained mesostasis. The coarse subhedral crystals suggest a rather slow growth over a relatively long period of time (> 100 y) (Friedman-Lentz et al 1999, Day et al. 2006) within a sub-surface magma chamber while microcrystals in the mesostasis correspond to a faster cooling stage as crystal mushes were extruded to the surface. It is noteworthy that for a lava flow to spread out, the crystal to melt ratio may not exceed $50 \%$; this implies that nakhlites accumulated phenocrysts after emplacement. The previously studied nakhlites show subtle differences (mesostasis proportions, cumulus crystal compositions and overgrowths, cristallinities of the mesostasis), which allows them to be positioned within a lava pile with some stratigraphic order from MIL 03346, the uppermost part of the pile, down to NWA 998 at the base of the flow (Mikouchi et al 2003, Treiman 2005 and references therein). Crystal settling and increasing compaction throughout the nakhlite pile likely occurred after extrusion 

03346 and range 1 to $6^{\circ} \mathrm{C}$ /hour (Sautter et al. 2002, Hammer and Rutherford 2005).

Thus nakhlites would have cooled at the Martian surface over short periods of time from 8 to 48 days (Day et al. 2006). The discovery of NWA 5790 offers additional information to better constrain the formation of nakhlite in the magma chamber and extrusion conditions onto the surface. In this paper, we present the petrology, mineralogy and geochemistry of NWA 5790, and compare this new find with the other nakhlites to discuss: (1) the crystallization conditions of cumulus augite in the nakhlite magma chamber, (2) the status of olivine in the Nakhlite Parental Magma, and (3) the final position of NWA 5790 within the pile at the Martian surface.

\section{ANALYTICAL METHODS}

Freshly broken pieces of NWA 5790 were polished to obtain two thick sections $\boldsymbol{A}$ and $\boldsymbol{B}$ of $0.75 \mathrm{~cm}^{2}$ and $0.63 \mathrm{~cm}^{2}$ respectively (Fig. 1). Additional broken pieces were preserved for wet chemical analysis.

Microscopic observations and quantitative chemical analyses of the various phases were made on the polished sections of NWA 5790. Backscattered electron (BSE) images were taken with a Zeiss Supra 55 scanning electron microscope (SEM) equipped with an energy dispersive spectrometer (EDS) at UPMC. Chemical maps were performed using a Bruker QUAD EDS detector and software Quantax at $15 \mathrm{kV}$ and $36 \mathrm{nA}$ (about $300000 \mathrm{cps}$ ). Electron microprobe (EMP) analyses were performed with a Cameca SX100 (WDS) at UPMC (CAMPARIS). Operating conditions were: $15 \mathrm{kV}$ accelerating voltage with a probe current of $10 \mathrm{nA}$, a counting time of $10 \mathrm{~s}$, and a focused beam for all phases but feldspar and glass (defocused at $4 \mu \mathrm{m}$ ). Natural 
118 orthoclase (K); diopside (Mg, Si, Ca); anorthite (Al); $\mathrm{MnTiO}_{3}(\mathrm{Mn}, \mathrm{Ti}) ; \mathrm{Cr}_{2} \mathrm{O}_{3}(\mathrm{Cr})$;

$119 \mathrm{Fe}_{2} \mathrm{O}_{3}(\mathrm{Fe}) ; \mathrm{NiO}(\mathrm{Ni})$; apatite $(\mathrm{P})$; pyrite $(\mathrm{S})$. Analyses of a reference Atlantic MORB

120 glass (CH98-DR12) and Celessou and San Carlos olivines permit to avoid systematic

121 deviations outside the reported uncertainty (Baghdadi et al., 2015). The analytical

122 reproducibility of the EMP data is $0.5 \%$ relative for $\mathrm{Si}$ (olivine, augite) and 1-3\%

123 relative for elements present in excess of $1 \mathrm{wt} . \%$. It is better than $30 \%$ relative for

124 elements on the order of $0.1 \%$. The composite color picture (Fig. $1 \mathrm{~b}$ ) is a WDS X-

125 ray map acquired on the CAMECA SX100 electron microprobe at Laboratoire

126 Magmas et Volcans, Blaise Pascal University (France). Analytical conditions were:

$12720 \mathrm{kV}$ accelerating voltage, $100 \mathrm{nA}$ beam current, $10 \mu \mathrm{m}$ defocussed beam, and $40 \mathrm{~ms}$

128 dwell time. Raw intensity maps were combined into RGB pictures.

129 For in-depth analysis of oscillatory zoning in olivine and augite specific

130 procedures were applied as the relative variations from one point to the next were

131 only several times the analytical uncertainty) (see electronic supplement). Chemical

132 oscillations of short wavelength are reported about the mean local value, which

133 permits to show at the same scale, variations of small amplitude from the core and the

134 rim with strongly different compositions. These variations of small amplitude are not

135 visible on BSE images for two reasons: because of the overall much larger

136 compositional variations on one hand and the short scale (a few micrometers). Under

137 specific tuning of the SEM, some oscillatory zoning can be seen on restricted areas

138 (see online supplement). There are several ways of presenting small chemical

139 variations:

140 - Oxide wt.\% as obtained from EMPA. In this case instrumental noise

141 (resulting from polishing, focusing, current instability, etc.) may overcome the 
142 chemical signal. This way is often preferred as it avoids error correlation (the sum is 143 not $100 \%)$.

144 - As a.p.f.u. (Atom per formula unit) based on a fixed number of cations.

145 Doing so we minimize instrumental errors (e.g. current instability is the same for all

146 cations during one single analysis) but we may introduce spurious variations (e.g. Si

147 in olivine will vary simply because of analytical errors on the other cations and vice $148 v e r s a$ ). This problem will arise every time a closure condition (i.e. constant sum of 149 cations) is introduced.

150 - As a.p.f.u. with a free number of cations. This is equivalent to working with

151 oxide wt. \% but permits statistical calculations were all cations have the same weight.

152 For instance, a variable $\mathrm{Mg} / \mathrm{Fe}$ ratio does not change the number of $\mathrm{Si}$ atoms. In the

153 case of olivine variations in Si will result from analytical errors only (P and Al which

154 could substitute for Si are significantly below the analytical error on $\mathrm{Si}$ ).

155 We preferred this last way of presenting data, nevertheless all methods should yield

156 the same results if the variations are robust, i.e. outside the error bars (see online

157 supplement). Our preferred method permits verifying that $\mathrm{Si}$ is constant in olivine,

158 that the sum $(\mathrm{Mg}+\mathrm{Fe})$ is constant to the first order and $(\mathrm{Mg}+\mathrm{Fe}+\mathrm{Ca}+\mathrm{Mn})$ is constant

159 to the second order. We can therefore introduce statistical tests on the data to assess to

160 what extent these rules are observed, and similarly check whether the variations of

$161 \mathrm{Mg}$ (for instance) are outside the error bars. We applied these procedures to reference

162 samples (e.g. San Carlos olivine) and NWA 5790 alike.

163

164 The mesostasis of NWA 5790 was analyzed with EMP using a specific

165 procedure. The beam was operated in raster mode with a current of $40 \mathrm{nA}$, over areas 166 of 250x150 micrometers. According to SEM images, mesostasis is partly crystallized 
and the composition of the mesostasis from spot analysis is meaningless (no reproducibility); we therefore expected that areas as large as possible would yield an average composition. In order to assess the validity of this assumption 14 areas were analyzed. The error is estimated from $\sigma / \mathrm{n}^{1 / 2}$, were $\sigma$ is the standard deviation and $\mathrm{n}$ is the number of areas investigated. For the purpose of comparison, we analyzed the mesostasis on a section of MIL $03346(, 123)$ and a section of NWA 817 under similar conditions. Due to the smaller size of the mesostasis pools in NWA 817, the rastered areas were smaller (100 x 60 micrometers). In order to obtain a similar representative data set for NWA 817, the number of rastered areas was increased to 53. Consistency of the results was checked by analyzing pyroxene and olivine cores using the same procedures in all three sections. Note that low totals are inherent to the procedure: cracks and voids in the mesostasis cannot be avoided in scanning mode; focusing is not perfect because of soft silicates (e.g. glass).

The modal composition has been estimated from pixel counting on BSE images, using 29 images of 3 Mpixels each (magnification x50) and one image of the whole section of 23 Mpixels. For estimating phase abundance in the mesostasis, 9 additional pictures at higher magnification $\left(0.25 \mathrm{~mm}^{2}\right.$ each, magnification $\left.\mathrm{x} 200\right)$ were considered.

A 500 mg fragment of NWA 5790 was powdered using a boron carbide mortar and pestle. Major elements were determined at the Universite de Bretagne Occidentale in Brest (France), by ICP-AES (inductively coupled plasma-atomic emission spectrometry) using the procedure described by Cotten et al. (1995). The accuracy of this system is better than $5 \%$, and the reproducibility better than $3 \%$. Trace element concentrations were measured at the Institut Universitaire Européen de la Mer 
192 (IUEM), Plouzané (France), by ICP-MS (inductively coupled plasma-mass

193 spectrometry) using a Thermo Element 2 spectrometer following the procedure

194 described by Barrat et al. (2012). Based on standard measurements and sample

195 duplicates, trace element concentration reproducibility is generally better than $5 \%$,

196 except for W, which is generally better than $10 \%$. Two splits were analyzed. Trace

197 element analysis by laser ablation ICP-MS in NWA 5790, MIL 03346 and NWA 817

198 complements the above set of major elements. The analytical procedures are those

199 described in Barrat et al. (2009).

200 Magnetic properties of a $1.16 \mathrm{~g}$ fragment were studied using standard techniques

201 described in Rochette et al. (2005). These include measurement of magnetic

202 susceptibility, and hysteresis properties. In addition the fabric of NWA 5790 has been

203 investigated through measurement of the anisotropy of magnetic susceptibility (AMS)

204 of the same fragment using standard measurement techniques described in Gattacceca

205 et al. (2008). This technique is non destructive and allows measurement of the three-

206 dimensional fabric on bulk samples. It is representative of the preferred orientation of

207 magnetic minerals (magnetic fabric), which in magmatic rocks is generally

208 representative of the overall rock fabric (Tarling and Hrouda, 1993).

209

210 3. RESULTS

\section{3.1. Petrography}

214 NWA 5790 is a medium grained rock with dominant millimeter sized euhedral

215 phenocrysts of augite $(0.3-2 \mathrm{~mm})$ (Fig. 1) with length not exceeding $2 \mathrm{~mm}$. A few

216 subhedral olivine phenocrysts with similar size $(1-3 \mathrm{~mm})$ are found concentrated at 
217 the $\operatorname{rim}$ of section $A$, and dispersed in section $B$. A few microphenocrysts of

218 titanomagnetite are also present. The mesostasis is abundant, with typical pocket size

219 on the order of 0.5-3 mm. The mode (vol. \%) is as follows: Clinopyroxene $57.8 \pm 4 \%$,

220 mesostasis $36.3 \pm 3 \%$, olivine $5.6 \pm 5 \%$, (barely enough to make it an orthocumulate),

221 titanomagnetite $0.3 \pm 0.2 \%$, where the statistical error is at the 2-sigma level. The large

222 relative error on olivine abundance results from the presence of only 5 and 9 large

223 phenocrysts in all of sections $A$ and $B$ respectively. However our olivine mode is

224 within errors of results published previously for the same rock (Tomkinson et al.

225 2015). The texture of NWA 5790 strongly recalls NWA 817 and MIL 03346 but the

226 abundance of the mesostasis is the highest ever described in a nakhlite.

\section{/Fig. 1. Global BSE Image/}

229 Augite exhibits a thin Fe-enriched rim when in contact with the mesostasis (Fig.1 and

230 2). This rim thickness is about 10-30 micrometers, depending on crystal orientation

231 with respect to the polished section surface (Fig. 2). Such a rim, already described in

232 other nakhlites, becomes thinner or absent when in contact with other cumulus grains

233 such as olivine, augite or titanomagnetite. In NWA 5790 rims are particularly sharp

234 compared to those in all other nakhlites including NWA 817 (10-50 micrometers) and

235 MIL 03346 (70-100 micrometers). Contrast enhancement shows that most of the

236 augite cumulus crystals exhibit unusual irregular recurrent zoning absent in the other

237 nakhlites (possibly cryptic in NWA 817). They exhibit resorbed cores with an

238 irregular shape overgrown by a less magnesian composition. Rounded augites are

239 included in olivine indicating that its resorption was followed by incorporation in

240 growing olivine before the final overgrowth of augite (Fig. 1B). These fragments 
241 exhibit the typical irregular zoning but are devoid of the Fe enriched rim indicating

242 that olivine growth occurred before the last stage of rim pyroxene growth.

243 The only shock effect observed is mechanical twinning. Augite contains few melt

244 pockets of trapped mesostasis similar to those described in MIL 03346 (Sautter et al 245 2006).

\section{/Fig. 2 contrasted BSE Image/}

248 Olivine varies in size from macrocrysts (about $2 \mathrm{~mm}$ ) slightly larger than cumulus

249 augite to smaller grains and appears unevenly distributed in the studied sections. One 250 small anhedral crystal is observed in the center of section $A$ (Fig. 1). Olivine is

251 euhedral when abutting mesostasis and it lacks the dark lamellar symplectite 252 exsolution (augite-magnetite intergrowths) observed in Nakhla and Governador 253 Valadares (Greshake et al 2000; Mikouchi et al. 2000). 254

255 Fracturing of pyroxene and olivine is moderate like in other nakhlites and unlike any 256 shergottites. Olivine unlike augite is steadily zoned with a Fe-enriched rim on the 257 order of 50 micrometers similar to what is observed in MIL 03346 and sharper 258 compared to NWA 817 (about 100 micrometers). Neither orthopyroxene nor 259 pigeonite is observed replacing olivine, like in NWA 817 and MIL 03346. One 260 olivine crystal (section $B$ ) contains a large magmatic inclusion rich in Cl-amphibole 261 (nearly one third of the inclusion) and apatite similar to those described in MIL 03346 262 (Sautter et al., 2006). Rare melt inclusions may be present at the rim of augite when 263 included in olivine. 
264 One titanomagnetite euhedral phenocryst is present in section $A$ (Fig. 1B) containing

265 ilmenite exsolution and a significant magmatic inclusion with pigeonite, $\mathrm{Na}$ and $\mathrm{K}$

266 feldspar, and apatite.

267 Thin amphibole films can be found within fractures of augite. Its aspect is different

268 from the iddingsite observed in other nakhlites, as it is clearly not a low temperature

269 alteration product of its host.

270 Interstitial mesostasis is much more abundant in NWA 5790 than in all the other

271 nakhlites, about 36 vol. \% compared to $20 \%$ in MIL 03346, the uppermost nakhlite in

272 the pile until now. Mesostasis contains dendritic cross-shaped oxides, Fe-rich

273 pyroxene and fayalitic olivine set in a glassy, poorly crystallized, feldspathic and

274 silicic groundmass (Fig. 2). Plagioclase laths as seen in most other nakhlites (Treiman

275 2005) are lacking, as in MIL 03346. Mesostasis titanomagnetite amounts to $0.6 \pm 0.2$

276 vol. \%, dendritic chains of iron-rich olivine and pyroxene $3.4 \pm 0.8 \%$ and glass, silica

277 and feldspar $31.9 \pm 0.9 \%$. The olivine and pyroxene chains in the mesostasis are about

$278 \quad 2-4 \mu \mathrm{m}$ wide and form a striking rectangular pattern. Submicrometric exsolutions of

279 ilmenite amount to about $10 \%$ of host titanomagnetite. The small size of the phases

280 and the intermediate and variable compositions of glass make it difficult to distinguish

281 accurately between glass, silica, and zoned K-feldspar or albitic plagioclase. One

282 occurrence of chalcopyrite has been observed as in Nakhla (Greenwood et al. 2000).

\subsection{The anisotropy of magnetic susceptibility (AMS)}

286 The three-dimensional petrofabric of NWA 5790 was investigated using the

287 anisotropy of magnetic susceptibility (AMS). Previous studies (e.g., Gattacceca et al.

288 2008) concluded that in basaltic shergottites and nakhlites, AMS might be a proxy of 
289 the original magmatic fabric. Here we present AMS data for NWA 5790. We also

290 provide data for other nakhlites that were not studied in Gattacceca et al. (2008): Y-

291 000593, NWA 817, and additional data for MIL 03346.

292 A synthesis combining these new results together with previous data (Collinson,

293 1997; Gattacceca et al., 2008) is presented in table 1. The AMS is characterized by $P_{f}$,

294 the ratio of maximum to minimum ferromagnetic susceptibility (Gattacceca et al.,

295 2008), and the shape parameter T (Jelinek, 1981) ranging from -1 for prolate fabric

296 (well-developed lineation) to +1 for oblate fabric (well-developed foliation).

298 /Table 1: Magnetic properties of nakhlites/

299 The magnetic fabric of nakhlites is oblate (foliated texture) with a mean $\mathrm{T}$ of 0.32 ,

300 which is expected for a cumulate, and in agreement with the observed rock texture

301 and preferred orientation of augite crystals (e.g., McSween, 1994). The degree of

302 anisotropy $\mathrm{P}_{\mathrm{f}}$ ranges from 1.005 to 1.040 (average 1.023, standard deviation 0.010 )

303 with NWA 5790 having the lowest value at $\mathrm{P}_{\mathrm{f}}=1.005$. It is noteworthy that based on

304 petrological criteria, NWA $998\left(\mathrm{P}_{\mathrm{f}}=1.031\right)$ and Lafayette $\left(\mathrm{P}_{\mathrm{f}}=1.040\right)$, the most

305 anisotropic samples, have been suggested to be the deepest samples of the nakhlite

306 igneous body, with a burial depth $>30 \mathrm{~m}$ (Mikouchi et al., 2006). We propose that

307 higher lithostatic load resulted in a more developed magnetic foliation with respect to

308 other nakhlites. Conversely, the very low magnetic anisotropy of NWA 5790

$309 \quad\left(\mathrm{P}_{\mathrm{f}}=1.005\right)$ may indicate a very shallow origin for this meteorite, shallower than the 1-

$3102 \mathrm{~m}$ that is the depth estimated for NWA 817 (Mikouchi et al., 2006).

\section{$311 \quad 3.3 \quad$ Mineralogy}

312 Representative compositions of the most significant phases are reported in tables 2-8 


\section{/ Table 2 Augite analyses/}

Augite exhibits unusual core compositions not observed in any of the other nakhlites. In NWA 5790, augites display irregular recurrent zoning mostly due to $\mathrm{FeO} / \mathrm{MgO}$ variations. Zones of comparatively high Fe alternate with relatively Fe-poor zone with irregular boundaries $\left(\mathrm{Mg} \#\right.$ varies between 0.54 and 0.63, $\mathrm{En}_{35-38} \mathrm{Fs}_{25-22} \mathrm{Wo}_{40}$ and $\mathrm{Fe} / \mathrm{Mn}=40-32$ ). Irregularity of zoning can be observed in BSE images: in Figure 2, ghost augite rich in $\mathrm{Mg}$ (dark grey) with variable composition (Mg\# 61-58) and with irregular boundary is surrounded by augite poorer in $\mathrm{Mg}$ (light grey, $\mathrm{Mg} \#$ 55-50). The outermost rim enriched in $\mathrm{Fe}$ (white) against the mesostasis may be absent. In the same crystal the transition from $\mathrm{Mg}$ rich core to the less $\mathrm{Mg}$ rich overgrowth may be either discontinuous or steady depending on which part of the crystal is concerned. EMP traverses performed across augite crystals (Fig. 3) show that Al, Ti, Cr and Mn anticorrelate with Mg\#. Ca and $\mathrm{Na}$ remain nearly constant (Table 2). These heterogeneous cores are surrounded by rims of hedenbergite composition up to $\mathrm{En}_{20} \mathrm{Fs}_{43} \mathrm{Wo}_{36}$ (and $\mathrm{Fe} / \mathrm{Mn}=45-40$ for $\mathrm{Mg} \#=20-50$ ) (Fig. 3). Ca decreases and increases again at the very rim only slightly. A similar, though more marked feature has been observed in MIL 03346 exclusively, whilst in other nakhlites as Fe increases Ca decreases as well, giving rise to a pigeonitic rim. In NWA 5790 the $\mathrm{Al}_{2} \mathrm{O}_{3}$ content increases to 4 wt. $\%$ towards the rim as the $\mathrm{Mg} \#$ decreases from 0.6 to 0.2 ; the $\mathrm{TiO}_{2}$ content exhibits a similar trend, with low 0.2 to $0.6 \mathrm{wt} . \%$ in the core and enrichment up to 1.6 wt. \% at the rim of $\mathrm{Mg} \#$ 0.2. In contrast to $\mathrm{Al}$ and $\mathrm{Ti}$, the $\mathrm{Cr}_{2} \mathrm{O}_{3}$ content decreases from 0.38 wt. \% down to below detection. The overall composition of 
337 augite can be visualized in the conventional pyroxene quadrilateral (Fig. 4) and

338 compared to augite compositions in MIL 03346.

339 /Fig. 3 Cpx Ol zoning/

340 /Fig. 4 Cpx quadrilateral/

341 Superimposed on the overall zoning, EMP analyses reveal a faint oscillatory zoning

342 for major and minor elements, including the $\mathrm{Mg} \#, \mathrm{Si}, \mathrm{Mg}, \mathrm{Ca}, \mathrm{Fe}, \mathrm{Al}$ with a

343 wavelength on the order of $15 \mu \mathrm{m}$, from the core to the rim (Fig. 5a). The oscillations

344 are for atoms per formula unit (p.f.u.) (See on line supplement). The wavelength

345 observed is independent of the sampling step, which was varied by a factor 10 . One

346 wave always corresponds to several data points (sampling step down to 1

347 micrometers) and several waves are observed. The same will be shown for olivine

348 (see below) though at a different wavelength. Therefore cyclic variations of the

349 background noise cannot be responsible for such oscillations.

350 Despite a similar wavelength, no simple correlation is observed between the various

351 elemental variations. The amplitude of oscillatory zoning is too small to be visible on

352 BSE images. Oscillatory zoning in lavas is usually interpreted as the result of

353 disequilibrium due to rapid growth. MIL 03346 is the only nakhlite where oscillatory

354 zoning restricted to rim pyroxene was previously noted (Anand et al. 2005).

355 In the mesostasis of NWA 5790, acicular intercumulus pyroxene is Fe-enriched with

356 variable composition (about $\mathrm{En}_{11} \mathrm{Fs}_{49} \mathrm{Wo}_{34} \mathrm{Ku}_{4} \mathrm{Ti}-\mathrm{Tsch}_{1}$ and $\mathrm{FeO} / \mathrm{MnO}=46$ ). It is

357 enriched in aluminum (Tschermak components).

359 Olivine (Table 3) 
362 Olivine cores are homogeneous and exhibit the same composition from one crystal to 363 the next, $\mathrm{Fa}_{65.5 \pm 0.5}$ with $\mathrm{Fe} / \mathrm{Mn}=47 \pm 3(\mathrm{n}=142)$. The rim with a thickness on the order 364 of 50 micrometers is zoned from $\mathrm{Fa}_{65}$ to $\mathrm{Fa}_{90}$ with increasing Fe/Mn to 40 (Fig. 3).

365 This rim is quite thin, being a factor of 10 smaller than the crystal radius (more than

$366500 \mu \mathrm{m})$. Clearly the primary olivine core composition is preserved and is not affected 367 by possible late exchange with the melt.

368 Interestingly, this core composition is more fayalitic than those preserved in olivine 369 from MIL 03346, NWA 817, and Y-000593, the uppermost rocks of the nakhlite pile, 370 and similar to that of NWA $998(\mathrm{Mg} \#=0.35)$. The small interstitial olivine crystals of 371 the mesostasis are fayalitic and show the same composition as the megacryst rim $372\left(\mathrm{Mg \# =}\right.$ ). The most ferroan composition of olivine in the mesostasis is $\mathrm{Fa}_{93}$.

373 At first sight, the $\mathrm{CaO}$ content in olivine megacrysts does not show significant 374 variations and remains between 0.5 and 0.6 wt. \%. However EMP analyses reveal Ca, $375 \mathrm{Mn}, \mathrm{Mg}$ and Fe oscillatory zoning with a wavelength of about 3 micrometers similar 376 to what is observed in pyroxene (Fig. 5b) (see on line supplement). In figure 5b we 377 present the variations of $\mathrm{Mg}$ about a local average (long range filtering; see on-line 378 supplement) as it permits to include the variations of the rim.

379 Oscillations are present in both core and rim of olivine. Detailed description of 380 oscillatory zoning is beyond the scope of this paper; still, as will be seen below this 381 result has far reaching implications and therefore deserves an in-depth presentation 382 (see also on line supplement). The most important point at this stage is to prove that 383 the observed variations are real and not due to background noise. The case of olivine 384 is the easiest for the purpose of the demonstration. From the structural formula of 385 olivine $(\mathrm{Mg}, \mathrm{Fe})_{2} \mathrm{SiO}_{4}$ we expect that, when expressed on a molar basis, $\mathrm{Si}$ and $386(\mathrm{Mg}+\mathrm{Fe})$ should be constant. From careful chemical analyses we know that the 
contributions of $\mathrm{Al}$ and $\mathrm{P}$, which could substitute for $\mathrm{Si}$, are less than the analytical error (one sigma) for Si. Therefore Si should be constant within analytical errors, which is what is observed. For $(\mathrm{Mg}+\mathrm{Fe})$ we observe some substitution by $\mathrm{Ca}$ and $\mathrm{Mn}$ which are not negligible but represent less than $3 \%$ of the $(\mathrm{Mg}+\mathrm{Fe})$ total. Therefore we can neglect this contribution in the following discussion. A statistical analysis of the results indicates that the variations of $\mathrm{Mg}$ and $\mathrm{Fe}$ are negatively correlated which cannot be explained by random analytical errors (counting statistics) or systematic errors (which would imply a positive correlation).

This result is important as it means that chemical diffusion in olivine was negligible as it would have erased these short wavelength variations; zoning at the rims of phenocrysts must result from the closed system evolution of melt composition and olivine overgrowth, not from diffusional exchange with the melt (subsolidus or not).

\section{/Fig. 5 Augite + Olivine oscillatory zoning/}

\section{Mesostasis}

Mesostasis is dominated by either plagioclase ( $\mathrm{An}_{20} \mathrm{Ab}_{72} \mathrm{Or}_{8}$ on average) or Kfeldspar $\left(\mathrm{An}_{13} \mathrm{Ab}_{25} \mathrm{Or}_{65}\right.$ on the average) compositions which exhibit significant variability (Table 4) with silica and glassy silica-rich compositions. Crystallinity is variable, with some mesostasis pools containing a significant fraction of silicafeldspathic glass (Fig. 6). Note that all phases in the mesostasis, including olivine, augite, plagioclase, silica and oxides exhibit low EMP totals. This is because of the small size and/or dendritic aspect of the phases.

\section{Fig 6 : BSE image of mesostasis/}


411 The average compositions of 12 mesostasis pockets have been measured in scanning

412 mode, which permits the determination of an average mesostasis composition

413 including all dendritic crystals. Results are reported in Table 5 and compared with the

414 mesostasis

415 /(Table 4 mesostasis silicates/

416 /Table 5 mesostases)/

417 compositions of MIL 03346 and NWA 817 measured using a similar procedure.

418 The first interesting feature is the close similarity of the mesostases in all three

419 nakhlites. According to the different thickness of overgrowths of augite and olivine in

420 the different rocks, we did expect that mesostasis composition would be affected in

421 proportion to the respective fractions of mesostasis and overgrowth. As this is not the

422 case, we must conclude that overgrowths predate some compaction of the melt

423 included in intercumulus pools, and that the amount of presently observed mesostasis

424 represents the same final melt evolution and not a variable intracumulus evolution.

425 Alteration products

426 The product of olivine, augite and mesostasis alteration as found in most other

427 nakhlites (iddingsite/smectite) (Gillet et al. 2002; see also Treiman 2005 and

428 references therein) is absent in NWA 5790 (Tomkinson et al. 2015). Instead we find

429 in some augite and olivine fractures, in a different textural setting, a product of

430 unspecified mineralogy, which we infer to be a mixture of amphibole and smectite of

431 variable composition (Fig. 7; Table 6). The low totals may be due to the

432 microcrystalline and/or hydrous nature of the phases. One type is low in $\mathrm{Al}$ and high

433 in $\mathrm{Ca}$ and $\mathrm{Fe}$ with a rather high $\mathrm{Mg \#} \mathrm{(27} \mathrm{-} \mathrm{59);} \mathrm{it} \mathrm{is} \mathrm{neither} \mathrm{olivine} \mathrm{nor} \mathrm{smectite.} \mathrm{The}$

434 second is high in $\mathrm{Al}, \mathrm{Na}$ and $\mathrm{K}$, lower in $\mathrm{Ca}, \mathrm{Fe}$ and $\mathrm{Mg}$. Its low $\mathrm{Mg} \#$ (7 to 20)

435 suggests a late (possibly hydrothermal) crystallization. Both types contain variable 
436 amounts of $\mathrm{Cl}$ from 0 to 3 wt. \%. A plot of $\mathrm{Cl}$ against $\mathrm{Al}$ (not shown) reveals the 437 existence of a chlorine rich type in addition to the low- and high-Al types already 438 mentioned; interestingly the composition of this type is similar to the amphibole 439 described by Sautter et al. (2006) in MIL 03346. The average composition of the Cl

440 rich compositions is displayed in Table 6 suggesting that it likely is a mixture with 441 dominant amphibole. Subtraction of the Al-rich component from the Cl-rich 442 composition yields a composition similar to the amphibole of MIL 03346.

443 /Fig 7: BSE image of alteration products /

444 Table 6: Amphibole compositions/

445 Additional minor phases and magmatic inclusions are described in the on line 446 supplement.

Oxides (Table 7)

Rare Ti-magnetite phenocrysts $\mathrm{Uv}_{32} \mathrm{Mt}_{56} \mathrm{Sp}_{7} \mathrm{Ct}_{4}$ (a solid solution of ulvöspinel, 453 magnetite, spinel and chromite) show fine ilmenite exsolutions, too small to be 454 analyzed accurately with EMP. The fraction of $\mathrm{Fe}^{3+}$, calculated after stoichiometry, is 455 significant with $\mathrm{Fe}^{3+} /\left(\mathrm{Fe}^{3+}+\mathrm{Fe}^{2+}\right)=0.47 \pm 0.01$. They differ from dendritic 456 microcrysts in the mesostasis pockets which exhibit a wider compositional range:

457 Uv52-74Mt38-19Sp2-1 (see Table 7), $\mathrm{Fe}^{3+} /\left(\mathrm{Fe}^{3+}+\mathrm{Fe}^{2+}\right)=0.33-0.18$, and contain 458 more $\mathrm{Ti}$, and are $\mathrm{Al}$ and $\mathrm{Cr}$ free. The high $\mathrm{Fe}^{3+}$ fraction partly explains the low totals 
459 of table 7. In the mesostasis the crystals are dendritic (Fig. 6 ) which represents

460 another analytical difficulty contributing to the low totals. Still the calculated

461 structural formulae provide a satisfactory stoichiometry.

462

463 Rock magnetic properties of nakhlites: The mineralogy of magnetic minerals of

464 rocks can be studied by magnetic measurements. Magnetic properties of SNC

465 meteorites, apart from NWA 5790, have been reviewed by Rochette et al. (2005). We

466 provide here the magnetic properties for NWA 5790. Low-field magnetic

467 susceptibility (that represents the contribution of ferro-, para-, and diamagnetic

468 minerals) is $\chi=6.4810^{-6} \mathrm{~m}^{3} . \mathrm{kg}^{-1}$, the high-field susceptibility (that represents the

469 contribution of para- and diamagnetic minerals only) is $\chi \mathrm{hf}=4.0210^{-7} \mathrm{~m}^{3} \cdot \mathrm{kg}^{-1}$.

470 Saturation remanence is $\mathrm{Mrs}=297 \mathrm{mAm}{ }^{2} \cdot \mathrm{kg}^{-1}$, saturation magnetization is $\mathrm{Ms}=$

$4711.19 \mathrm{Am}^{2} \cdot \mathrm{kg}^{-1}$, coercivity is $\mathrm{Bc}=32 \mathrm{mT}$, coercivity of remanence is Bcr $=58 \mathrm{mT}$.

472 Ms corresponds to 1.3 wt. \% of pure magnetite (or more if impure). Magnetite as

473 microphenocrysts is not abundant (about 0.3 vol. \%) which suggest that Ti-magnetite

474 in the mesostasis was underestimated by modal estimation.

475

476

477

\subsection{Bulk Rock Geochemistry}

479 Major and trace element analyses were measured on separate splits and are reported in

480 Table 8. To enable an easier comparison with other nakhlites, analyses of NWA 817

481 (Sautter et al. 2002), MIL 03346 (this work) and Nakhla (Nakamura et al. 1982) are

482 also reported. Key element ratios, which are identical to those measured in other 
483

484

nakhlites, confirm unambiguously the Martian origin $\left(\mathrm{FeO} * / \mathrm{MnO}=38, \mathrm{Na}_{2} \mathrm{O} / \mathrm{Al}_{2} \mathrm{O}_{3}=\right.$ $\left.0.39, \mathrm{~K} / \mathrm{La}=476, \mathrm{Ga} / \mathrm{Al}=3.510^{-4}\right)$. Bulk major element chemistry reflects the abundance of mesostasis: it is somewhat poorer in $\mathrm{Mg}$ and $\mathrm{Fe}$ and is richer in $\mathrm{Na}, \mathrm{K}$, and $\mathrm{Al}$ compared to the other nakhlites: $\mathrm{MgO}=8.0 \%$ and $\mathrm{Al}_{2} \mathrm{O}_{3}=5.3 \%$ instead of $11.8 \%$ and $1.6 \%$ for Nakhla. Otherwise NWA 5790 appears chemically similar to MIL 03346.

\section{/Table 8 Bulk rock major and trace element analysis/}

The REE (Rare Earth Element) pattern (Fig. 8A) is characterized by a strong light REE enrichment: $(\mathrm{La} / \mathrm{Yb})_{\mathrm{n}}=5.5$, and a minor negative Eu anomaly $\mathrm{Eu} / \mathrm{Eu}^{*}=0.86$. NWA 5790 displays the highest Th, U (Fig. 8B) and REE abundances (Fig.8A) ever reported for a nakhlite (e.g., $\mathrm{Th}=0.85 \mathrm{ppm})$.

Weathered finds from the Sahara generally exhibit marked Ba enrichments that are sensitive indicators of the development of terrestrial secondary phases (e.g., Barrat et al., 2003). The high $\mathrm{Ba}$ value (285 ppm) and $\mathrm{Ba} / \mathrm{Rb}$ ratio (39) compared to MIL 03346 (57 ppm and 13) (Fig. 8B) (Day et al. 2006) are strong arguments supporting contamination for this element. Other analyzed trace elements however do not exhibit detectable enrichment due to this effect. One interesting characteristics of NWA 5790 and other nakhlites as well, is illustrated in an $\mathrm{Sr}_{\mathrm{vs}} \mathrm{Al}_{2} \mathrm{O}_{3}$ plot (Fig. 9). The ratio of Sr to $\mathrm{Al}_{2} \mathrm{O}_{3}$ is high due to the low $\mathrm{Al}_{2} \mathrm{O}_{3}$ content, especially when compared with shergottites and CI Chondrite. A simple interpretation of this feature is melting at high pressure for the source of nakhlites or melting of an Al depleted source, the Al depletion being in both cases the signature of melting with residual garnet. The difference between these two possibilities could be resolved using $\mathrm{Nd}$ isotopic data. 
508

\section{/Fig. 9 Sr vs $\mathrm{Al} 2 \mathrm{O} 3 /$}

LA-ICP-MS analyses of pyroxene, mesostasis and olivine of NWA 5790 are compared to similar analyses in NWA 817 and MIL 03346 (Table 8; Fig. 10). The mesostasis of NWA 5790 contains a high incompatible element abundance like either NWA 817 or MIL 03346 as illustrated by the REE patterns. Variable concentrations (a factor of 2) but identical patterns can be observed in augite. There is no obvious relationship between REE abundance and position in the crystal but the Fe-enriched rims are too thin to be analyzed.

/Table 9 Trace element of separate minerals/

\section{/Fig. 10 REE in phases/}

\section{REE in augite}

The average REE patterns in NWA 5790, NWA 817 and MIL 03346 are very close to one another with abundances increasing from MIL to NWA 5790 (Fig. 10). When looking more closely at the different patterns however, subtle differences appear. The abundances among the different data points in one single section are quite variable: on the average the abundances increase by $1.72,1.69$ and 1.29 in MIL, NWA 5790, and NWA 817 respectively but this effect is slightly more pronounced for La, the most incompatible element which increases by a factor of about 2 in all three samples. This should however be considered with care since the number of analytical points is limited and may not document the whole range in each sample. At the same time the $\mathrm{Ce} / \mathrm{Yb}$ ratio among the different data points increases by $18 \%$ (NWA 5790), $36 \%$ (MIL), $57 \%$ (NWA 817): the pattern is nearly similar (NWA 5790) to slightly fractionated (NWA 817) as the composition evolves. The concentrations in all pyroxenes analyzed exceed those recorded in Nakhla augite by Nakamura et al. 
533 (1982). As the augite composition reflects the composition of the melt it crystallizes

534 from, one should conclude that the melt changed composition significantly. The

535 spatial resolution does not permit to decide whether this is a continuous process (e.g.

536 fractional crystallization) (Day et al. 2006, Wadhwa and Borg 2006) or a

537 discontinuous one (magma mixing) or both.

REE in olivine.

540 The REE patterns in olivine are different in NWA 817, MIL 03346 and NWA 5790

541 (Fig.10). The two olivines analyzed in NWA 817 differ in their Light REE

542 abundances. If we consider the REE pattern in the smectite of NWA 817 (Gillet et al.,

543 2002), Ol1 (enriched in light REE) can be derived from $\mathrm{Ol} 2$ with the addition of about

$544 \quad 3-5 \%$ of smectite, the exact amount depending on the variable composition of the

545 smectite. The HREE pattern is likely to result from olivine composition (not smectite)

546 as it is similar in the two olivines analyzed, whereas the LREE pattern results from

547 variable amounts of smectites trapped in olivine, a conclusion similar to that obtained

548 by Wadhwa and Borg (2006). The HREE of olivine in NWA 5790 are

549 undistinguishable from NWA 817 whereas the LREE are significantly lower. This

550 implies the absence of smectite in NWA 5790 olivine, which would increase the

551 abundance of LREE. Finally in MIL 03346 neither the LREE nor the HREE match

552 those of NWA 5790 olivine, except for $\mathrm{Lu}$ and $\mathrm{Yb}$. Our results are quite similar to

553 those reported by Day et al. (2006). Nevertheless the pattern is enigmatic and the

554 contribution of smectite is not supported by the data of Gillet et al. (2002). Although

555 the results for smectite in MIL are not available, a very odd composition of smectite

556 would be required in order to obtain the pattern of MIL olivine (Stopar et al., 2013).

557 In other words the REE pattern in olivine most likely reflects the magmatic history in 
558 NWA 5790, smectite incorporation in NWA 817, and contamination by smectite or 559 other phases in MIL 03346.

560

\section{4. DISCUSSION}

563

564

565

566

567

568

569

570

571

572

573 (2012).

574 This new nakhlite, however, displays at least four specific features that may shed new

575 light on nakhlite petrogenesis: 1) cumulate clinopyroxene complex zoning; 2) olivine 576 578 the three magmatic features mentioned above.

Like all the other nakhlites, NWA 5790 exhibits a typical cumulate texture, which is reflected in its chemical composition. Phenocrysts of olivine and augite settled down and trapped some intercumulus liquid. NWA 5790 resembles quite closely MIL 03346: it exhibits the same large crystal size, large amount of Ti-magnetite, high mesostasis fraction made of glass and skeletal Fe-augite, Fe-olivine and Ti-magnetite, and lack of plagioclase laths. According to its even higher mesostasis fraction and lower anisotropy, NWA 5790 can therefore be viewed as the uppermost part of the nakhlite lava flow (Mikouchi et al., 2003). Launch pairing with the other nakhlites is likely based on the 9.6 Ma cosmogenic age determined for NWA 5790 (Huber et al. core composition; 3) mesostasis proportion; 4) lack of secondary low temperature alteration. As no iddingsite occurs in the sections studied we will focus exclusively on

\section{$579 \quad 4.1$ Augite zoning}

\subsubsection{Recurrent internal zoning}


581 Augite core compositions in NWA 5790, compared to all the other nakhlites, suggest 582 a somewhat different petrogenesis or different cooling conditions before extrusion as 583 a thick lava flow onto the Martian surface. Core augite relates to an early stage of 584 crystallization within a magma chamber (core 1 in Fig. 3 and Table 2). The presence 585 of numerous glomerocrysts indicates that augites were accumulated before their final 586 stage of growth. When enclosed in olivine augite grains are rounded, indicating that 587 they suffered significant resorption before being overgrown, a conclusion supported 588 by their unusual zoning. The Fe-enriched rims are observed in several nakhlites whilst 589 the internal recurrent zoning is described for the first time and corresponds to an early 590 phenomenon not observed elsewhere in the pile. Discontinuous zoning evidences one 591 stage of augite resorption and rounded augite enclosed in olivine corresponds to cores 592 of such crystals without the overgrowth. Transient chemical disequilibrium between 593 the early cumulus phenocrysts and the final liquid composition in the chamber may 594 account for partial augite resorption. Still, despite a moderate compositional 595 difference between the new melt batch and the former one (as recorded in the overall 596 compositions or the two parts of the cores) augite was significantly and irregularly 597 resorbed. This implies at least two stages of growth with some resorption in-between. 598 The second stage permitted the recovery of euhedral shapes. The overgrown core 599 (core 2 in Fig. 3 and Table 2) is depleted in $\mathrm{MgO}$ relative to the previous core, 600 indicating that the new melt batch had a lower Mg\#. Treiman (2005) suggested for 601 other nakhlites that a slight $\mathrm{Mg} \#$ depression in the Mg-rich cores could result from 602 hollow core crystallization. A similar depression in the Mg-rich part of the augite 603 (core 1 in Fig. 3) probably corresponds to that case. Infilling and overgrowing hopper 604 crystals would be a good way to make patchy zoning but this would not produce the 605 rounded crystals included in olivine. If this scenario applied to the other nakhlites, one 
606 should distinguish between a rim significantly enriched in iron corresponding to

607 intercumulus growth and an overgrowth surrounding a core of irregular shape. This

608 scheme is clearly visible in NWA 5790 and also in Nakhla (e.g. Goodrich et al. 2013,

609 their Fig. 11) but may not be present in all nakhlites: For example McKay et al.

610 (2006; their Fig. 1) observed a difference between MIL 03346 and Y-000593 based

611 on Al maps: augite cores in MIL appear homogeneous while Y-000593 looks similar

612 to NWA 5790.

613 The survival of core zoning (Fig. 2) indicates that clinopyroxenes in NWA 5790 were

614 stored where cooling was fast enough to preclude diffusive homogenization. This

615 feature contrasts with the absence of discontinuous zoning in the augite cores of some 616 of the other nakhlites (e.g. MIL 03346).

617 The composition of augite cores is marginally variable for five nakhlites (Nakhla,

618 Governador Valadares, Lafayette, Y-000593 and MIL 03346) with a narrow range in $619 \mathrm{Mg \#}$ from 62.5 to 62.9 respectively, suggesting a common parent melt. For the others 620 (NWA 998, NWA 817 and NWA 5790) the compositions depart significantly with $621 \mathrm{Mg \#}$ of 64.5, 66.5 and 60 respectively. As previously suggested (Treiman, 2005) this 622 supports the idea that the melt parent to the augites was not unique, but may 623 correspond to different stages of evolution of one single parent melt.

624 A more serious difficulty is whether olivine and augite in one single specimen derive 625 from the same parent melt. In the case of NWA 5790 it is quite clear that olivine and 626 augite cores are not in equilibrium suggesting that one at least is xenocrystic. For the 627 other nakhlites if we consider that the experimental results of Toplis and Caroll 628 (1995) are relevant, none of them appear to be at equilibrium, with MIL 03346 and Y629000593 departing least from equilibrium (Fig. 11). Augite overgrowths on the other 630 /Fig. 11 olivine and augite compositions compared/ 
631 hand appear to be in equilibrium with olivine (see, e.g., the analyses of augite and

632 olivine in contact with one another in NWA 817 by Sautter et al. (2002)). In the case

633 of NWA 5790, the resorbed habit of augite and its inclusion in olivine indicates that

634 olivine postdates augite. Rounded augites included in olivines can be found in other

635 nakhlites as well. The case is quite clear in NWA 817 and Nakhla (e.g. Fig. 4 in

636 Treiman et al. 2005) indicating that in at least three of the nakhlites both composition

637 and textural relationship indicate that augite is xenocrystic. In the other nakhlites there

638 is no evidence that the same does not apply. The only exception might be MIL 03346

639 where the augite appears unzoned (except for intercumulus overgrowth) and close to

640 equilibrium with olivine. The case of Y-000593 however where olivine and augite

641 appear close to equilibrium is different: McKay et al., (2006; their Fig. 1) showed

642 that augite cores exhibit resorption zoning and must therefore be considered as

643 xenocrystic

644

645

646 4.1.2. Rim Zoning.

647 The final rim of augite crystals was produced by crystallization from the final batch of

648 melt after crystallization of core olivine and in chemical continuity with augite

649 overgrowths (Fig. 3). The cores grew from an "infinite" reservoir whereas the rims

650 most probably correspond to growth in reservoir of limited size (compared to the

651 crystals), most likely the intercumulus liquid. The strong $\mathrm{FeO}$ enrichment of the rim

652 may partly reflect some disequilibrium growth due to strong undercooling. From the

653 mesostasis $\mathrm{FeO} / \mathrm{MgO}$ of 29 and the $\mathrm{K}_{\mathrm{D}}$ value of 0.18 (Toplis and Carroll, 1995) one

654 should expect a $(\mathrm{FeO} / \mathrm{MgO})$ Aug of about 5 compared to the observed value of 8 at the

655 very rim. This is exactly what is expected from a compositional gradient at the melt- 
656

657

658

659

660

661

662

663

664

665

666

667

668

669

670

671

672

673

674

675

676

677

678

679

680

crystal interface at rapid growth rate when diffusive transfer is limited in the melt.

The out-of-equilibrium composition of augite rim is another hint that the

compositional gradient at the augite rim is not due to diffusive exchange in the crystal

but to the evolution of the melt. We also note that the absence of diffusive exchange

in the crystal is supported by the preservation of core zoning (despite a longer time to

equilibrate) and the presence of oscillatory zoning at a wavelength of about 10 micrometers.

\subsubsection{Augite oscillatory zoning.}

Superimposed on the large wavelength zoning (core and rim) we observe small amplitude compositional variations with a wavelength of about 10-15 micrometers.

This results from the coupling of diffusion and growth and is typical of rapid out-of equilibrium growth (see, e.g., Allègre et al. 1981). Interestingly this suggests fast augite growth as well as sufficiently fast cooling conditions after crystallization to preclude diffusion and thus preserve the compositional variations. Our result is in qualitative agreement with the conclusions of Hammer and Rutherford (2005) and

Day et al. (2006) who derived fast cooling rates for MIL 03346 of $3-6^{\circ} \mathrm{C} / \mathrm{hr}$.

Theoretically, the wavelength of oscillatory zoning is scaled by the ratio $\mathrm{D} / \mathrm{V}$, where

$\mathrm{D}$ is the diffusivity in the melt and $\mathrm{V}$ the growth rate. The diffusions of all elements should be coupled since major and minor elements exhibit identical wavelengths. For a temperature of $1080^{\circ} \mathrm{C}$, a diffusivity of about $2 \times 10^{-13} \mathrm{~m}^{2} / \mathrm{s}$ can be inferred (Zhang, 1993) hence a large growth rate on the order of $1.3 \times 10^{-8} \mathrm{~m} / \mathrm{s}$, can be calculated. Accordingly, it would take about five hours for $0.5 \mathrm{~mm}$ augite crystals to grow under these conditions. Note that the wavelength is not accurately defined as it may slightly vary along a single profile: $\mathrm{D}$ and $\mathrm{V}$ depend on the composition at the interface and on 
681 its variations to the second order. The wavelength may also vary from one crystal to 682 the next due to various orientations of the profiles. The orientation effect is however 683 small (a factor of $<2$ at worst) on crystal sections with an aspect ratio significantly 684 different from unity, while the growth estimates are within one order of magnitude. 685

\subsection{Olivine zoning}

\subsubsection{Olivine bulk zoning}

689 Olivine cores in NWA 5790 are not in equilibrium with augite cores, to an even larger 690 extent when compared to the other rapidly cooled samples from the pile such as MIL 69103346 and NWA 817. Using the experimentally based correlation between the Mg\# of coexisting liquid, augite and olivine with decreasing temperature (Fig. 12) derived

693 from the experimental results of Toplis and Carroll (1995), a Mg\# of 58 in augite 694 should be in equilibrium with a Mg\# of 20 in liquid and a Mg\# of 40 in olivine at a temperature of $1092{ }^{\circ} \mathrm{C}$ (Treiman 1986-93, Longhi and Pan 1989; Harvey and

696 McSween $1992 \mathrm{a}-\mathrm{b})$.

697

700 Therefore olivine of $\mathrm{Mg} \# 35$ is out of equilibrium with any melt that precipitated

701 augite cores. Given the textural relationship between olivine and augite (resorbed 702 augite is included in olivine) the addition of augite from some external source to the 703 nakhlite parental melt (with or without olivine) is mandatory. Olivine however should be in equilibrium with the augite overgrowth. This feature has already been noticed 
705 for other nakhlites (Berkley et al., 1980; Nakamura et al., 1982; Treiman, 1986;

706 Longhi and Pan, 1989; Harvey and McSween 1992 b; Sautter et al. 2002).

707 Olivine core compositions (Mg\#=35) in NWA 5790 are among the most iron rich

708 compositions recorded in nakhlite olivine cores and is close to the composition of

70934.8 and 33.9 observed in Governador Valadares and Lafayette (Fig. 4). The

710 composition of the augite cores being totally different confirm, that augite and olivine

711 cores cannot be in equilibrium in at least one of these rocks.

712 The rim thickness in olivine megacrysts (about $50 \mu \mathrm{m}$ ) is 5 to 20 times smaller than

713 crystal radius (0.2 to $1 \mathrm{~mm})$. According to the sharp rim of olivine in NWA 5790, the

714 observation by Treiman (2005) that "in general, the highest the Mg\# of olivine core,

715 the sharpest the Mg zoning in the rim" seems fortuitous. The growth of olivine from

716 the melt must have been significant in order to include zoned pyroxene. In other

717 words, the final melt is not parental to the augite cores but it should be the parent of

718 olivine, and the augite overgrowths (Olivine $\mathrm{Mg} \# 35$, Cpx-overgrowth $\mathrm{Mg \# 50}$ and

719 mesostasis Mg\# 0.16; Fig. 12). This is probably the case for all nakhlites as shown in

720 Fig. 11, where olivine and augite core compositions are plotted: some data points fall

721 close to the equilibrium line, but most of them depart significantly therefrom.

722 In order to explain the disequilibrium between olivine and augite cores already

723 observed in other nakhlites, one hypothesis, strongly suggests that olivine

724 composition results from diffusive re-equilibration between olivine and late-stage

725 interstitial melt or subsolidus equilibration with the mesostasis (e.g., Longhi and Pan,

726 1989; Harvey and McSween 1992a, Mikouchi et al. 2003 and Sautter et al. 2002). As

727 already noticed in NWA 817 (Sautter et al. 2002), the progressively truncated zoning

728 of olivine when in contact with augite precludes subsolidus diffusion: This feature

729 indicates that zoning formed while both olivine and augite where still growing one 
against the other. In the case of NWA 5790 this explanation is impossible at least from obvious textural evidence (olivine core composition is primary as the "characteristic diffusion length" (= rim thickness) of $50 \mu \mathrm{m}$ (Fig. 3) is significantly smaller than the crystal radius of $400-500 \mu \mathrm{m})$.

As expected however, the augite overgrowth and olivine when in contact with each other are equilibrated. Moreover, rare melt inclusions trapped in-between are also in equilibrium (Fig. 12).

\subsubsection{Olivine oscillatory zoning}

Subsolidus exchange is not supported by our observations. i) If the olivine rim composition resulted from diffusive exchange, then we should observe a steady profile, with an equilibrium composition at the crystal melt interface: from a mesostasis $\mathrm{FeO} / \mathrm{MgO}$ of 28.8 , a $(\mathrm{FeO} / \mathrm{MgO})_{\mathrm{Ol}}$ should be 8.6 compared to the actual value of 13. ii) Oscillatory zoning with a wavelength of about $3 \mu \mathrm{m}$ (in olivine) should not have survived a diffusive exchange extending over $50 \mu \mathrm{m}$ (the rim thickness).

The wavelength of oscillatory zoning in olivine does not differ strongly from that observed in augite (10 micrometers). As mentioned above, it can be scaled to $\mathrm{D} / \mathrm{V}$. Diffusivity in the melt is to the first order independent of the growing crystals, olivine and augite. The growth rates of olivine and augite are expected to be of the same order of magnitude since the crystals exhibit about the same size. We can calculate an olivine growth rate of about $7 \times 10^{-8} \mathrm{~m} / \mathrm{s}$ at $1080^{\circ} \mathrm{C}$ during its major growth stage. 
756 Chemical mapping of major and trace elements using the EDS equipment on the

757 SEM, permits the observation of sharp chemical gradients at the rims of both olivine 758 and augite, especially for $\mathrm{P}$ whose diffusivity in the melt is reputedly sluggish (Fig.

759 13). This feature indicates that growth rates were particularly rapid and diffusion 760 could not erase such compositional excesses, neither during nor after growth. This 761 feature is typically observed in experiments where quenching is possible but rarely

762 under natural conditions. Subsolidus exchange in the melt (glass), if any, should have 763 been much faster in the melt than in the crystals; subsolidus diffusion conflicts with 764 this observation.

\section{5 /Fig. 13: Chemical map Fe:Ti:P/}

\section{$766 \quad 4.3 \quad$ Mesostasis abundance}

767 Mesostasis abundance relates to the packing efficiency or burial depth. Compared to 768 other nakhlites, NWA 5790 is characterized by the high abundance of mesostasis, 769 which is reflected in the overall chemical composition as well. The mesostasis of 770 NWA 5790 is indistinguishable from that of MIL 03346 or NWA 817: the 771 interspecimen variations are of the same magnitude as those recorded for one single 772 sample and correspond to the analysis of a more or less crystallized fraction. The 773 composition of the whole rock indicates a large fraction of intercumulus liquid and 774 the highest REE content. Mesostasis abundance, whole rock composition, thin olivine 775 and augite rims, skeletal crystals and glassy proportion of the mesostasis indicate that 776 NWA 5790 experienced the fastest cooling of any nakhlite. It thus supersedes MIL 77703346 at the top of a nakhlite pile (Mikouchi et al, 2003). 


\subsection{Oxygen fugacity.}

There are two classical ways of assessing the oxygen fugacity in SNCs. A first approach uses the composition of coexisting oxides (ilmenite and titanomagnetite). Szymanski et al. (2010) obtained oxygen fugacities in the range QFM to QFM-1 at a closure temperature of $710-810^{\circ} \mathrm{C}$ for four different nakhlites. Unfortunately, the same calculation cannot be applied here for two reasons: i) the ilmenite exsolutions in titanomagnetite phenocrysts are too small to be analyzed accurately with EMP. ii) the titanomagnetite composition in the mesostasis differs from the phenocrysts and is highly variable, indicating that equilibrium did not prevail during this phase of crystallization.

\section{Eu to Gd ratio and oxygen fugacity}

A second way of assessing the oxygen fugacity is from the ratio of Eu to $\mathrm{Gd}$ in augite and coexisting melt, following McKay et al. (1994). Doing so, we assume that the mesostasis composition does not differ significantly in REE pattern from that of the melt from which augite crystallized. We obtain IW+3 ( \pm 0.5$)$ (or QFM -0.5$)$ assuming a magmatic closure temperature (about $1050^{\circ} \mathrm{C}$ ). All three nakhlites studied fall within $0.1 \log$ unit, a very restricted range. These results compare quite well with those of Szymanski et al. (2010) who gives values of QFM -0.8 to +0.1 for four other nakhlites using the Fe, Ti-oxide oxybarometer, despite the fact that the latter are for much lower temperatures $\left(780\right.$ to $\left.710^{\circ} \mathrm{C}\right)$. However, if core augite is xenocrystic this procedure may not be legitimate.

\section{Magnetic properties and oxygen fugacity}

The magnetization of previously studied nakhlites is carried by titanomagnetite in variable amounts from about 0.3 to 1.5 wt. \% (pure magnetite equivalent; Rochette et 
805

806

807

808

809

810

811

812

813

814

815

816

818

819

820

821

823

824

825

826

828

829

al. 2005). NWA 5790 shows intrinsic magnetic properties coherent with other nakhlites (Gattacceca et al., 2014) but with the highest magnetization of all nakhlites except MIL 03346 (which has a slightly higher saturation magnetization Ms but lower susceptibility, see Table 1). Among nakhlites, two groups, magnetite-rich and poor, correspond to MIL 03346-NWA 5790 and Governador-Lafayette-Nakhla, respectively, suggesting that the magnetite content, and thus oxygen fugacity, roughly increases up the magmatic pile. However, the deepest sample (NWA 998) appears also quite magnetite-rich, in an intermediate group with NWA 817 and Y-000593. Magnetite grain-size, as indicated by coercivity parameters, is homogeneous among nakhlites, two samples exhibiting significantly coarser grains: NWA 998 and Y000593. Y-000593 is unlike other nakhlites, as a significant magnetic contribution arises from pyrrhotite (Funaki et al., 2002). Ms is potentially a more robust way than microscopy to estimate the amount of titanomagnetite present, as the grain size does not influence the estimate, while microscopy has a difficult time quantifying grains below $10 \mu \mathrm{m}$ size. Magnetic domain state in NWA 5790 is pseudo-single domain with average magnetic grain size of the order of $1 \mu \mathrm{m}$ (however, magnetic grain size may be smaller than real grain size if the grain exhibit ilmenite lamellae). On the other hand calculating the amount of titanomagnetite from Ms (instead of the pure magnetite equivalent mentioned above) necessitates the knowledge of average substitution. Assuming an average substitution of Uv63 in titanomagnetite based on the few mesostasis analyses, leads to a titanomagnetite specific Ms of $45 \mathrm{Am}^{2} / \mathrm{kg}$ (instead of 92 for pure magnetite). Therefore the measured Ms translates into $2.6 \mathrm{wt}$. $\%$ titanomagnetite, or 1.6 vol. \%. This is slightly larger than the modal analysis estimate ( 0.3 vol. $\%$ as phenocrysts and 0.6 vol. $\%$ as fine grains in the mesostasis). This discrepancy is easily accounted for by the underestimated content of oxide in the 
mesostasis based on microscopic imaging. The higher content indicated by magnetism is coherent with the rather high content of $\mathrm{TiO}_{2}$ in the bulk mesostasis analyses: 1.03 wt. \% which corresponds to $5 \%$ Ti-magnetite in the mesostasis or $2.4 \%$ in the bulk rock (1.8 in the mesostasis plus $0.6 \%$ as phenocrysts) in fairly good agreement with the estimate from magnetism.

\subsection{Primary melt composition}

According to their different phenocryst compositions, the eight different nakhlites may be derived from consanguineous parent melts differentiated to different extents. First of all, we must state clearly what parent melt means. If olivine and augite are not equilibrated they must have had two different parent melts, whose composition may be estimated.

Inferring nakhlite parental melts is difficult as these rocks are cumulates. For NWA 5790 we derived the parent melt compositions using a four step procedure: i) Add the adcumulus growth (augite and olivine rims) to the analyzed bulk mesostasis composition. ii) Add to this melt composition, the appropriate quantity of augite and olivine phenocrysts that precipitated in equilibrium with the melt. iii) Add more olivine and subtract some augite (core composition) to account for their partial resorption. iv) Add olivine until we obtain a melt composition in equilibrium with the

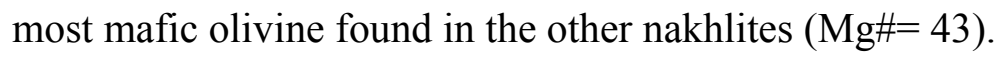

Step 1: To obtain the melt composition before rim crystallization of olivine and augite (adcumulus growth) we need to add the appropriate amounts of Fe-rich crystal rims. This requires the knowledge of i) the ratio of melt (mesostasis) to crystals (rims) and ii) the relative proportion of olivine and augite adcumulus growth. From the BSE 
856 images only, these ratios cannot be obtained accurately as the overgrowth rims of both

857 olivine and augite are discontinuous and the conversion of surface to volume ratio is

858 not straightforward in this particular case. The melt to crystal rim ratio is better

859 constrained by equilibrium considerations $(\mathrm{Mg} \#)$, the addition of olivine and augite

860 (Mg\# of 47 and 28 for augite and olivine respectively) yields an instantaneous melt in

861 equilibrium with phenocryst rim. The augite to olivine ratio is constrained by the $\mathrm{CaO}$

862 content of the augite, which must reproduce the observations. We add olivine and

863 augite in equilibrium with the melt incrementally to the mesostasis composition, and

864 iterate step-by-step using a parameterized composition of both olivine and augite

865 derived from the data of Toplis and Carroll (1995). The best fit is obtained for a mass

866 fraction of crystals of $18 \%$ with a mass ratio of augite to olivine of $91: 9$. This

867 intermediate composition (J1) is listed in Table 10. At this stage we obtain $\mathrm{Mg \#}$ of

86828.3 and 47.0 for olivine and augite, respectively.

869 Step two consists of adding more augite and olivine to the melt until reaching an $\mathrm{Mg \#}$

870 of 36 for olivine and 53 for augite in equilibrium with the melt. The difference with

871 the last intercumulus growth stage is the augite to olivine ratio, which is expected to

872 vary from about, 91:9 (as in the previous step) to 0:1, corresponding to the point when

873 augite starts being resorbed. The best solution is obtained for another 7-wt. \%

874 crystallization, but the ratio of augite to olivine must be kept at 95:5 in order to keep

875 an acceptable augite composition. We obtain $\mathrm{Mg \#}$ of 53.6 and 36 for augite and

876 olivine respectively. The composition of this equilibrium melt (J2) is listed in Table

87710.

878 For steps three and four the scenario has to be changed to account for augite

879 dissolution, which predates olivine crystallization rather than being coeval as

880 suggested initially. After this event olivine and augite precipitated simultaneously 
881 with a constant mass fraction in the solid. The presence of olivine on the liquidus is

882 probably due to decompression, while augite is saturated but with a composition

883 different from that having been resorbed.

884 How much augite was dissolved is the only remaining question. The amount of augite

885 is totally unconstrained except that the superheat necessary to dissolve augite is

886 limited. More importantly, by subtracting augite (the dissolved fraction) it is

887 impossible to generate melts that could be in equilibrium with the more mafic crystals

888 observed in the other nakhlites or even with the core of augite xenocrysts found in

889 NWA 5790. We must conclude that augite are true xenocrysts that crystallized

890 previously from a less evolved melt.

891 To summarize, from the mesostasis composition we can calculate successive melts:

892 before adcumulus crystallization (J1), before crystallization of olivine and augite (J2).

893 For the sake of illustration we calculate the melt composition before the dissolution of

$8946 \%$ core augite $(\mathrm{J} 3)$ but as mentioned above this choice is not constrained. The

895 compositions J1-J3 are reported in Table 10 and can be compared with previous

896 estimates from the literature (Treiman, 1986-1993; Longhi and Pan 1989; Harvey and

897 McSween 1992 b; Treiman et al. 1998; Treiman and Goodrich, 2001; Varela et al.

898 2001; Stockstill et al. 2005; Sautter et al. 2012).

899 The estimated parental melt obtained by this four-steps procedure, is drastically

900 different from previous estimates for several reasons (Table 10). The major reason is

901 that we constrained the parental melt to be in equilibrium with core olivine, whereas

902 core augite is considered to be xenocrystic. Previous workers assumed that the

903 parental melt was in equilibrium with core augite and considered that olivine

904 compositions (even the cores) resulted from secondary diffusional equilibration with 
905 the melt. In the case of NWA 5790, core augites are obviously xenocrystic and

906 secondary diffusional equilibration of olivine can be rejected.

907

908 Therefore one obvious question arises: can we derive the melt composition in

909 equilibrium with augite cores and can this melt after some evolution be parent to

910 olivine phenocrysts? Depending on the extent of the melt evolution augite and olivine

911 cores will be close to, or far from equilibrium with one another.

912

913 TTable 10: Parent melt composition/

914

915 Application of the model to other nakhlites:

916 For the other seven nakhlites, in agreement with compositions estimated by Treiman

917 (1986) and investigated by Pan and Longhi (1989) the last magma batch had olivine

918 on its liquidus and not augite, which favors the above scenario for the other nakhlites

919 as well, whereas most authors assumed that augite was on the liquidus.

920

921 Unlike augite cores, olivine core compositions of the different nakhlites vary

922 significantly (from Mg\# 35 to 43) (Fig. 4) which suggests that they were derived from

923 different magma batches, a possibility already suggested but usually refuted because

924 of the too tenuous evidence (Treiman, 2005). It is possible that some of the variability

925 between the different nakhlites relates to variable amounts of resorbed augite. It

926 follows that the composition we derived (J2) can be valid for the last magma batch

927 from which NWA 5790 crystallized after the last (minor) resorption of augite. Our

928 parent melt estimates differ significantly from estimates for the other nakhlites as we

929 consider here olivine as phenocrystic and augite as xenocrystic. Still the question of

930 the melt parent to augite cores remains. The augite core compositions in the different 
931 nakhlites vary slightly from $\mathrm{Mg \#}=62.5$ to 62.9 in Nakhla, Governador Valadares,

932 Lafayette, Y-000593 and MIL 03346, to significantly different values of 64.5 in

933 NWA 998, and 66.5 in NWA 817 on one hand and 60 in NWA 5790 on the other.

934 Therefore the melts parent to the augite cores are certainly less variable than the melts

935 parent to olivine, which are fractionated to variable extents.

936 The melt parent to augite cores can be calculated using the same procedure as above.

937 Starting from J2 we incrementally add augite and olivine. Doing so we make a

938 systematic error as we neglect augite resorption (out of equilibrium) and replace this

939 process by less augite crystallization (at equilibrium). We obtain the composition J4

940 (Table 10) that is in equilibrium with the most mafic pyroxenes cores of NWA 817.

941 The less mafic augite cores would correspond to intermediate melt compositions. Not

942 surprisingly this composition falls within the range of the other parent melts, however

943 the amount of $\mathrm{CaO}$ and $\mathrm{FeO}$ are low and $\mathrm{Al}_{2} \mathrm{O}_{3}$ is too high. The degree of

944 crystallization necessary to obtain this composition starting from $\mathrm{J} 2$, is $22 \%$ augite

945 and no olivine, a moderate amount. The trace element composition of this melt will

946 not be strongly different from the mesostasis as illustrated by the $\mathrm{K}_{2} \mathrm{O}$ content which

947 is decreased from $1.6 \%$ in the mesostasis to $1.04 \%$ in $\mathrm{J} 4$. This $\mathrm{K}_{2} \mathrm{O}$ content is

948 intermediate between that obtained by Treiman and Goodrich (2001) and other

949 workers (Table 10). The former value was derived from the composition of melt

950 inclusions in olivine while the latter was derived mostly from pyroxene compositions.

951 It is worth pointing out that the absence of a Eu anomaly in the mesostasis proves that

952 plagioclase was not significantly fractionated. The nakhlite parent melts J4 has a

953 normative composition of $42 \%$ feldspar, $41 \%$ pyroxene and $14 \%$ olivine and an

$954 \mathrm{Mg \#}$ of 30.5. This cannot be the product of melting of a normal mantle (i.e. a mixture 955 of dominant olivine, pyroxene and minor plagioclase). At a low melting fraction, the 
956 melt will be devoid of normative olivine whereas at very high melting fractions

957 (necessary for a high olivine content) the feldspar fraction should be very low. This

958 particular melt composition results from a strong $\mathrm{FeO}$ enrichment in the source, which

959 makes olivine far more fusible than in more $\mathrm{MgO}$ rich sources; alternatively the

960 parent melt (J4) is already fractionated to a significant extent. These inferences are

961 based on the primitive Martian mantle estimates (Longhi et al. 1992; Sanloup et al.

962 1999; Ghosal et al. 1998) with an Mg\# of 72-80 indicating that the melt was not a

963 primitive mantle product (e.g. Treiman 2005).

964

965

\subsection{NWA 5790 petrogenesis}

967 The petrogenesis of nakhlites has been the concern of a number of previous works

968 (see Treiman, 2005 and references therein). Since we consider that augite cores are

969 xenocrystic, previous petrogenetic scenarios must be modified.

970 In a first stage augite crystals ( $\mathrm{Mg \#}$ of 60) grew alone from a relatively evolved, $\mathrm{Fe}-$

971 rich mafic melt at depth, forming augite glomerocrysts in a cumulate layer at the

972 bottom of a magma chamber, as indicated by their close association in clusters

973 (notice that in a mature cumulate we should not be able to distinguish clusters)

974 (Treiman 1990; Sautter et al 2002, 2006). A subsequent magma batch disrupted this

975 crystal conglomerate during a violent event, breaking some of the augite crystals of

$976 \mathrm{Mg \#}$ 60. Augite being out of equilibrium with this new batch dissolved steadily

977 developing scalloped resorbed boundaries in addition to evidence of breakage. The

978 partial dissolution of the augite cumulate and significant decompression brought

979 olivine onto the liquidus and supercooled the melt significantly. Olivine (Mg\# 35)

980 precipitated. After partial augite resorption, a short episode of new augite 
981 crystallization occurred and crystals settled as soon as their size was large enough. It seems that olivine and augite resumed growth simultaneously or nearly so. Finally the crystals trapped in a new cumulate, finished their growth in a closed system forming thin rims around both augite and olivine. The cumulate cooled rapidly hindering compaction and permitting the preservation of a large fraction of mesostasis. The succession of augite crystallization alone and olivine plus augite crystallization can be understood if the two stages proceeded under different pressures. If the pressure exceeds that for the existence of a peritectic, then augite alone will precipitate. At lower pressure, the eutectic is displaced and olivine is on the liquidus, followed by augite.

The following scenario of nakhlite magma evolution has been extensively discussed previously. Because the texture and composition of NWA 5790 is quite similar, the reader is referred to the work of Day et al. (2006) for a complete discussion and additional details. The succession of events is as follows:

- a- partial melting, melt extraction and ascent of nakhlite parental magma from a LREE depleted mantle source (e.g. Shih et al. 1999). -b- crystallization of cumulus augite $\mathrm{Mg} \# 66-60$ at some depth in a magma chamber. According to the different compositions of augite cores in the eight nakhlites several batches of melts and compositional evolution are expected. -c- A final magma-mixing event produced the entrainment of cumulus crystals (augite) within the melt towards the surface. Decompression and partial augite dissolution brought olivine to the liquidus in a strongly supercooled melt. Augite growth resumed concomitantly. -d- Extrusion and surface emplacement as thick lava flows, crystal settling, compaction and decreasing degree of equilibration from bottom to top throughout the 
1006 nakhlite flow. A number of successive flows may account for the small differences

1007 between the different nakhlites ( $\mathrm{Mg \#}$ of augite and olivine) corresponding to

1008 successive flows in a lava pile. Successive flows also explain the lack of correlation

1009 between olivine composition and mesostasis abundance.

$1010 \quad$ NWA 5790 possibly represents a quenched margin with the fastest cooling

1011 rate. Since NWA 5790 is a cumulate, the magma parent to accumulation must have

1012 flowed away otherwise it would never have cooled fast enough in order to trap a

1013 significant fraction of vitrophyric mesostasis.

1014 -e- Secondary hydrothermal alteration after cooling of the flow.

1015 -f- Impact release of the nakhlites from Mars 10-11 Ma ago.

1016 The study of NWA 5790 sheds new light on stages b-d, providing evidence of a new

1017 magma batch with more evolved liquid composition compared to the nakhlite parent

1018 magma but still less evolved than intercumulus liquid that produced hedenbergitic

1019 overgrowth. Finally there is no trace of iddingsite formation, possibly replaced by

1020 discreet amphibole formation in association with smectite (?) in fractures. This

1021 observation suggests that NWA 5790 may have been buried at a greater depth when

1022 hydrothermal alteration occurred (higher temperature), and is best explained by NWA

10235790 belonging to the top-most position in the bottom-most flow (Figure 14).

1024

1025

1026

1027

1028

5. CONCLUSIONS 
1030 There is no doubt that NWA 5790 is a new nakhlite unpaired with any other

1031 previously studied nakhlites. It likely comes from the same magmatic complex on

1032 Mars, which has been ejected by one single impact event. It supersedes MIL 03346 as

1033 the least reequilibrated, the least compacted, and the fastest cooled nakhlite. It shows

1034 the lowest degree of preferred orientation of any nakhlite and shares with MIL 03346

1035 the highest Ti-magnetite amount and thus oxygen fugacity. It provides evidence for

1036 complex magma mixing prior to eruption to the surface recorded in augite cores with

1037 a residence time in the magma chamber short enough to prevent Fe-Mg

1038 homogenization. Olivine is not truly co-magmatic with augite since the latter

1039 exhibited two stages of growth separated by some resorption. A similar scenario may

1040 be true for some other nakhlites at least, where the olivine status has been discussed,

1041 especially those with a significant mesostasis fraction.

1042

1043 According to the texture and the chemical composition of phases in NWA 5790,

1044 augite appears to be xenocrystic while olivine is indigenous. It may be more accurate

1045 to say that the nakhlite magmas result from two stages of magmatic evolution: one at

1046 high pressure, parent to the mafic cores of augites, the other one at a much lower

1047 pressure parent to olivine and a second growth stage of augite. When compared to

1048 other nakhlites it appears that augite (Mg\# from 66 to 60) and olivine (Mg\# from 43

1049 to 34) differ among the different rocks and are in disequilibrium with one another to

1050 various extents. The olivine compositions indicate that the second stage parent

1051 magmas are differentiated to various extents. Melts parent to augite are less

1052 fractionated. The magma parent to NWA 5790, the most evolved nakhlite, can be

1053 derived from a more primitive melt, parent to the most primitive augites (in the other

1054 nakhlites) by fractional crystallization of augite (on the order of $30 \%$ ). The more 
1055 fractionated character of NWA 5790 compared to NWA 817 (for instance) can be

1056 accounted for by the fractionation of a significant amount of augite.

1057 The significant geochemical differences and their obvious consanguinity suggest that

1058 the different nakhlites correspond to periodic discharges from a magma chamber at

1059 depth where augite crystallized. After disrupting augite cumulates, the magma is

1060 expelled and olivine crystallizes during this last episode. Final accumulation of augite

1061 and olivine permits trapping of variable amounts of mesostasis depending on the

1062 extent of compaction (Fig. 14). Within one flow the position can be estimated from

1063 the mesostasis abundance. Therefore, NWA 5790 is probably from the topmost of one

1064 such flow according to its large mesostasis fraction. The absence of low temperature

1065 pervasive alteration (smectite/iddingsite) and the presence instead of a mixture of

1066 amphibole with hydrous phases suggests that it belongs to the deepest flow in the

1067 stack sampled so far. This scenario is summarized in figure 14: The different

1068 nakhlites are grouped in one top flow comprising MIL 03346, Y-000593 Governador

1069 Valadares, Lafayette and Nakhla with one single augite core composition and

1070 abundant smectite, an intermediate flow with NWA 817 and NWA 998 and a lower

1071 flow with NWA 5790.

1072 / Fig. 14 The nakhlite pile revisited/

1073

1074 Acknowledgements: A. Habibi is greatly acknowledged for donating the reference

1075 specimen of NWA 5790. We are indebted to Kevin Righter and the meteorite curation

1076 group for the loan of a polished section of MIL 03346. US Antarctic meteorite

1077 samples are recovered by the Antarctic Search for Meteorites (ANSMET) program,

1078 which has been funded by NSF and NASA, and characterized and curated by the

1079 Department of Mineral Sciences of the Smithsonian Institution and Astromaterials

1080 Curation Office at NASA Johnson Space Center. ENS Lyon is acknowledged for the

1081 loan of a polished section of NWA 817. J-P. Lorand provided a reference calibration 
1082 sample for olivine. R. Hewins corrected carefully our frenglish and made helpful

1083 suggestions. M. Fialin and N. Rividi are thanked for assistance on the microprobe. We

1084 thank C. Herd for the editorial handling and careful editing, J. Hammer and two

1085 anonymous reviewers for constructive comments. We gratefully acknowledge the

1086 Programme National de Planétologie (CNRS-INSU) for financial support. 


\section{References}

1089

1090

1091

1092

1093

1094

1095

1096

1097

1098

1099

1100

1101

1102

1103

1104

1105

1106

1107

1108

1109

1110

1111

1112

1113

1114

1115

1116

1117

1118

1119

1120

1121

1122

1123

1124

1125

1126

1127

1128

1129

1130

1131

1132

1133

1134

Allègre C.J., Provost A. and Jaupart C. (1981) Oscillatory zoning : a pathological case of crystal growth. Nature 294, 223-228.

Anand M., Williams C.T., Russell S.S., Jones G., James S., and Grady M.M. (2005) Petrology and Geochemistry of Nakhlite MIL 03346: A New Martian Meteorite From Antarctica. Lunar and Planetary Science Conference 36. Lunar Planet. Inst., Houston. \#1639(abstr.).

Baghdadi B. ,Jambon A., Barrat J-A. (2015) Metamorphic angrite Northwest Africa 3164/5167 compared to magmatic angrites. Geochim. Cosmochim. Acta, 168, 1-21.

Barrat J.A., Jambon A., Bohn M., Blichert-Toft J., Sautter V., Göpel C., Gillet Ph., Boudouma O., and Keller F. (2003) Petrology and geochemistry of the unbrecciated achondrite North West Africa 1240 NWA 1240: an HED parent body impact melt. Geochim. Cosmochim. Acta, 67, 3959-3970.

Barrat J. A., Yamaguchi A., Greenwood R. C., Bollinger C., Bohn M. and Franchi I. A. (2009) Trace element geochemistry of K rich impact spherules from howardites. Geochim. Cosmochim. Acta, 73, 5944-5958.

Barrat J.A., Zanda B., Moynier F., Bollinger C., Liorzou C., and Bayon G. (2012) Geochemistry of $\mathrm{Cl}$ chondrites: Major and trace elements, and $\mathrm{Cu}$ and $\mathrm{Zn}$ isotopes. Geochim. Cosmochim. Acta, 83, 79-92.

Berkley, J.L., Keil, K., Prinz, M. (1980). Comparative petrology and origin of Governador Valadares and other nakhlites. Lunar Planet. Sci. XI. Lunar Planet. Inst., Houston, 1089-1102.

Bertka, C.M., Fei, Y., (1997). Mineralogy of the martian interior up to core-mantle boundary pressures. J. Geophys. Res. 102, 52515264.

Collinson, D.W. (1997). Magnetic properties of Martian meteorites: implications for an ancient Martian magnetic field. Meteorit. Planet. Sci. 32, 803-811.

Cotten J., Ledez A., Bau M., Caroff M., Maury R. C., Dulski P., Fourcade S., Bohn M., and Brousse R. (1995). Origin of anomalous Rare-Earth Element and Yttrium Enrichments in Subaerially Exposed Basalts - Evidence from French-Polynesia. Chem. Geol. 119, 115-138.

Day J.M.D., Taylor L.A., Floss C., and McSween H. Y Jr. (2006) Petrology and chemistry of MIL 03346 and its significance in understanding the petrogenesis of nakhlites on Mars. Meteorit. Planet. Sci. 41, 581-606.

Dreibus G. and Wänke H. (1982) Parent body of the SNC meteorites: Chemistry, Size and Formation. Meteoritics 17, 207-208.

Friedman-Lentz, R.C., Taylor, G.J., Treiman, A.H., (1999). Formation of a martian pyroxenite: a comparative study of the nakhlite meteorites and Theo's Flow. Meteorit. Planet. Sci.. 34, 919-932 
1135

1136

1137

1138

1139

1140

1141

1142

1143

1144

1145

1146

1147

1148

1149

1150

1151

1152

1153

1154

1155

1156

1157

1158

1159

1160

1161

1162

1163

1164

1165

1166

1167

1168

1169

1170

1171

1172

1173

1174

1175

1176

1177

1178

1179

1180

1181

1182

1183

1184
Funaki M., Hoffmann V. and Imae N. (2009). Estimate of the magnetic field of Mars based on the magnetic characteristics of the Yamato 000593 Nakhlite. Meteorit. Planet. Sci. 44: 1179-1191.

Gattacceca J., Rochette P., Denise M., Consolmagno G., Folco L. (2005) An impact origin for the foliation of chondrites. Earth Planet. Sci. Lett. 234, 351- 368

Gattacceca J., Rochette P., Gounelle M., van Ginneken M. (2008) Magnetic anisotropy of HED and Martian meteorites and implications for the crust of Vesta and Mars, Earth Planet. Sci. Lett. 270, 280-289.

Gattacceca, J., P. Rochette, R. B. Scorzelli, P. Munayco, C. Agee, Y. Quesnel, C. Cournède, and J. Geissman 2014, Martian meteorites and Martian magnetic anomalies: A new perspective from NWA 7034, Geophys. Res. Lett., 41, doi:10.1002/2014GL060464

Ghosal, S., Sack, R.O., Ghiorso, M.S., Lipschutz, M.E., 1998. Evidence for a reduced, Fe-depleted martian mantle source region of shergottites. Contrib. Miner. Petrol. 130, 346-357.

Gillet P., Barrat J-A., Deloule E., Wadhwa M., A. Jambon A., Sautter V. , Devouard B., Neuville D., Benzerara K., Lesourd M. (2002).

Aqueous alteration in the Northwest Africa 817 (NWA 817) Martian Meteorite. Earth Planet. Sci. Lett. 203: 431-444.

Goodrich C.A., Treiman A.H., Filiberto J., Gross J. , and Jercinovic M.(2013) K2O-rich trapped melt in olivine in the Nakhla meteorite: Implications for petrogenesis of nakhlites and evolution of the Martian mantle. Meteoritics Planet. Sci. 48, 2371-2405.

Greenwood J.P., Mojzsis S.J., Coath C.D. (2000). Sulfur Isotopic Compositions of individual Sulfides in Martian Meteorites ALH84001 and Nakhla: Implications for Crust-regolith exchange on Mars. Earth Planet. Sci. Lett. 184: 23-35.

Greshake A., Stephan T. and Rost D.(2000) Combined TEM and TOFSIMS study of symplectiteexsolutions in olivine from the Martian meteorites Nakhla and Governador Valadarez. Lunar and Planetary Science Conference 31. Lunar Planet. Inst., Houston. \#1150 (abstr.).

Hammer J.E. and Rutherford M.J. (2005) Experimental crystallization of fe-rich basalt: Application to cooling rate and oxygen fugacity of Nakhlite MIL03346 Lunar Planet. Sci. XXXVI. Lunar Planet. Inst., Houston. \#1999(abstr.).

Harvey R. P. and McSween H. Y. (1992)a. Petrogenesis of the nakhlite meteorites: Evidence from cumulate mineral zoning. Geochim. Cosmochim. Acta 56: 1655-1663.

Harvey R. P. and McSween H. Y. (1992)b. The parent magma of the nakhlite meteorites: Clues from melt inclusions. Earth Planet. Sci. Lett.111: 467-482.

Huber L., Irving A.J.,Maden C. and Wieler (2012) R. Noble Gas Cosmic Ray Exposure Ages of four unusual Martian Meteorites:

Shergottites NWA 4797, NWA 5990, NWA 6342 and Nakhlite NWA 5790. Lunar and Planetary Science Conference 43 (Abstr.) 1408.

Imae N. and Ikeda Y. (2007). Petrology of the Miller Range 03346 
nakhlite in comparison with the Yamato 000593 nakhlite. Meteorit.

Planet. Sci. 42: 171-184.

Jambon A., Barrat J-A, O. Boudouma O., Fonteilles M., Badia D., Göpel

C. and Bohn M. (2005). Mineralogy and Petrology of the Angrite North West Africa 1296. Meteorit. Planet. Sci. 40: 361-375.

Jelinek V. (1981) Characterization of the magnetic fabric of rocks. Tectonophysics 79, 63-67.

Longhi, J., Pan, V., (1989). The parent magmas of the SNC meteorites. Lunar Planet. Sci. XIX. Lunar Planet. Inst., Houston. 451-464.

Longhi, J., Knittle, E., Holloway, J.R., Wänke, H., (1992). The bulk composition, mineralogy, and internal structure of Mars. In: Kiefer, H.H., Jakosky, B.M., Snyder, C.W., Matthews, M.S. (Eds.), Mars. University of Arizona Press, pp. 184-208.

McKay G., Le L., Wagstaff J. and Crozaz G.(1994) Experimental partitioning of rare earth elements and strontium: Constraints on petrogenesis and redox conditions during crystallization of Antarctic angrite Lewis Cliff 86010. Geochim. Cosmochim. Acta, 58. 2911-2919.

McKay G., Mikouchi T., and Schwandt C. (2006) Additional Complexities in Nakhlites Pyroxenes : a Progress (?) Report. Lunar and Planetary Science 37, \#2435

McSween, H.Y. Jr, (1994). What We Have Learned About Mars From SNC Meteorites. Meteoritics 29, 757-779.

Mikouchi, T., Yamada, I., Miyamoto, M., (2000). Symplectic exsolution in olivine from the Nakhla martian meteorite. Meteorit. Planet. Sci. 35, 937-942.).

Mikouchi T., Koizumi E., Monkawa A., Ueda Y., and Miyamoto M. (2003). Mineralogical Comparison of Y-000593 With Other Nakhlites: Implications for Relative Burial Depths of Nakhlites Lunar and Planetary Science Conference 35. Lunar Planet. Inst., Houston. \# (abstr.).

Mikouchi T., Miyamoto M., Koizumi E., Makishima J. and McKay G. (2006) Relative Burial Depths of Nakhlites: An Update. Lunar and Planetary Science Conference 37. Lunar Planet. Inst., Houston. (abstr.)\#1865.

Mikouchi T., Sugiyama K., Kato Y., Yamaguchi A., Kaneda K. (2009) Calcium Silico-Phosphate in Angrite revisited. 72nd Annual Meteoritical Society Meeting. Abstract 5351.

Nakamura N., Unruh D.M., Tatsumoto M. and Hutchison R. (1982). Origin and Evolution of the Nakhla Meteorite inferred From the $\mathrm{Sm}-\mathrm{Nd}$ and $\mathrm{U}-\mathrm{Pb}$ Systematics and REE, $\mathrm{Ba}, \mathrm{Sr}, \mathrm{Rb}$ and $\mathrm{K}$ Abundances. Geochim. Cosmochim. Acta 46 : 1555-1573.

Nyquist L. E., Bogard D. D., Shih C-Y., Greshake A., Stoffler D., and Eugster O. (2001). Ages and geologic histories of Martian meteorites. In Chronology \& Evolution of Mars (ISSI) 96:105-164.

Rochette P., Gattacceca J., Chevrier V. and Lorand J.P. (2005). Matching Martian crustal magnetization and meteorite magnetic properties, Meteorit. Planet. Sci., 40: 529-540.

Sanloup C., Jambon A., Gillet P.(1999) A simple chondritic model of Mars. Phys. Earth Planet. Int. 112 , 43-54. 
1234

1235

1236

1237

1238

1239

1240

1241

1242

1243

1244

1245

1246

1247

1248

1249

1250

1251

1252

1253

1254

1255

1256

1257

1258

1259

1260

1261

1262

1263

1264

1265

1266

1267

1268

1269

1270

1271

1272

1273

1274

1275

1276

1277

1278

1279

1280

1281
Sautter V., Barrat J-A., Jambon A., M. Javoy M., Lorand J-P., Gillet P., Joron J-L. \& Lesourd M. (2002). A new Martian meteorite from Morocco: the nakhlite North West Africa 817. Earth Planet. Sci. Lett. 195 : 223-238.

Sautter V., Jambon A., and Boudouma O. (2006). Cl-amphibole in the Nakhlite MIL 03346: Evidence for Sediment Contamination in a Martian Meteorite. Earth Planet. Sci. Lett. 252: 45-55.

Sautter V., Toplis M.J., Lorand J-P., and Macri M. (2012). Melt inclusions in augite from the nakhlite meteorites: A reassessment of nakhlite parental melt and implications for petrogenesis. Meteoritics \& Planetary Science 47, 330-344

Shih C.-Y., Nyquist L.E. and Wiesmann H. (1999). SamariumNeodymium and Rubidium-Strontium Systematics of Nakhlite Governador Valadares. Meteorit. Planet. Sci. 34 : 647-655.

Shih C.-Y., Wiesmann, H., Nyquist, L.E., Misawa, K., (2002). Crystallization age of Antarctic nakhlite Y-000593: further evidence of nakhlite launch pairing. NIPR Symposium on Antarctic Meteorites XXVII, 151-153.

Shih, C.-Y., Nyquist, L. E. \& Reese, Y. (2006). Rb-Sr and Sm-Nd Isotopic Studies of Antarctic Nakhlite MIL 03346. LPSC 37, (Abst.) \#1701.

Shih, C.-Y., Nyquist, L. E. \& Reese, Y. and Jambon A. (2010). Sm-Nd Isotopic Studies of two Nakhlites, NWA 5790 and NAKHLA. LPSC 41, (Abst.) \#1367.

Stockstill K. R., McSween H. Y., and Bodnar R. J. (2005). Melt inclusions in augite of the Nakhla Martian meteorite: Evidence for basaltic parental melt. Meteorit. Planet. Sci. 40, 377-396.

Szymanski A., Brenker F.E., Palme H. and El Goresy A. (2010) High oxidation state during formation of Martian nakhlites. Meteorit. Planet. Sci. 45, 21-31.

Tarling, D.H., Hrouda, F., (1993). The magnetic anisotropy of rocks. Chapman \& Hall, London. $217 p$

Tomkinson T., Lee M.R., Mark D.F., Dobson K.J.,Franchi I.A. (2015). The Northwest Africa (NWA) 5790 meteorite: A mesostasis-rich nakhlite with little or no Martian aqueous alteration. Meteorit. Planet. Sci. 50, 287304. doi: $10.1111 /$ maps. 12424

Toplis M. J. and Carroll M. R. (1995). An Experimental Study of the Influence of Oxygen Fugacity on Fe-Ti Oxide Stability, Phase Relations and Mineral-Melt equilibria in Ferro-Basaltic Systems. J. Petrol. 36:1137-1170.

Treiman A. H. (1986). The Parental Magma of the Nakhla Achondrite: Ultrabasic Volcanism on the Shergottite Parent Body. Geochim. Cosmochim. Acta 50: 1061-1070.

Treiman A. H. (1990). Complex petrogenesis of the Nakhla (SNC) meteorite: Evidence from Petrography and Mineral Chemistry. Lunar Planet. Sci.XX. Lunar Planet. Inst., Houston. pp. 273-280.

Treiman A. H. (1993). The parent magma of the Nakhla SNC) meteorite, inferred from magmatic inclusions. Geochim. 
1282

1283

1284

1285

1286

1287

1288

1289

1290

1291

1292

1293

1294

Cosmochim. Acta, 57: 4753-4767.

Treiman A.H. (2005). The Nakhlite Meteorites: Augite-rich igneous rocks from Mars. Chem. Erde, 65: 203-270.

Treiman A. H. and Goodrich C. (2001). A parent magma for the Nakhla Martian meteorite: Reconciliation of estimates from 1-Bar experiments, magmatic inclusions in olivine, and magmatic inclusions in augite (abstract \#1107). 32nd Lunar and Planetary Science Conference. Wadhwa M. and Borg L. E.,(2006) Trace Element and $\varepsilon^{142} \mathrm{Nd}$ Systematics in the Nakhlite MIL 03346 and the Orthopyroxenite ALH 84001: Implications for the Martian Mantle. Lunar and Planetary Science Conference 37, \#2045.

Zhang Y (1993) A Modified Effective Binary Diffusion Model. J. Geophys. Res. 98, 11901-11920. 
1297 Figure 1: a) BSE image of section A. Notice the dominant euhedral augites

1298 (light grey), a few subhedral olivines (OI) and large mesostasis pools with

1299 numerous dendritic crystals. Tm = titanomagnetite. B) False color image of

1300 section $B($ Red $=$ Ca, Green $=$ Fe, Blue $=$ Si. Notice the rounded augites

1301 included in olivines (end of white lines).

1302

1303 Figure 2: BSE image, detail of figure 1a, top right, contrast enhanced. Note

1304 the irregular zoning of augite and its iron enriched rim (white fringe). The

1305 mesostasis contains chains of olivine and ferro augite as well as a few oxides.

1307 Figure 3: Zoning profiles in both olivine and augite. Olivine cores exhibit a

1308 constant composition with an iron-enriched rim of about 50 micrometers,

1309 much thinner than in olivines of other mesostasis-bearing nakhlites. Augite

1310 cores are more complex, revealing successive growth stages (separated by

1311 the dashed lines). Note the slight Mg depression in the center of core 1 as

1312 already noted in some other nakhlites (see Treiman, 2005). Core 2 (Mg\# 54)

1313 corresponds to some overgrowth on the more magnesium rich core 1 (Mg\#

1314 58-60). The augite rim is only 30 micrometers wide and corresponds to

1315 closed system final growth.

1317 Figure 4: Augite compositions compared to MIL 03346 augites (core, rim and 1318 mesostasis; Day et al. 2006). Mesostasis crystals are generally too small to 1319 be analyzed by EMP. 
1321 Figure 5: Oscillatory zoning of both augite (a) and olivine (b). Notice the

1322 different scales and the different wavelengths of oscillations. a) Augite, same

1323 profile as figure 3. Concentrations for $\mathrm{Si}, \mathrm{Al}, \mathrm{Fe}$ and $\mathrm{Ca}$, as measured without

1324 corrections. b) Olivine. The Mg variations are corrected for long-range zoning

1325 and short-range noise (see on-line supplement). The presence of fine scale

1326 compositional oscillations in olivine indicates that rim zoning cannot result

1327 from subsolidus diffusional exchange. MgO range in olivine core $14.7 \pm 0.2$ wt.

$1328 \%$.

1330 Figure 6: BSE images of mesostasis shows chains of silicates (ferroaugite

1331 and fayalite), skeletal Ti-magnetite and poorly crystallized feldspathic

1332 background (black). The inset (top left) with higher brightness shows zoned

1333 feldspar in the mesostasis and interstitial silica-feldspathic glass (scale bar is

133420 micrometers).

1335

1336 Figure 7: BSE image of alteration (white) filling cracks in olivine and at the

1337 boundary between olivine and augite. The polyphase character of alteration

1338 product is visible in the inset.

1339

1340

1341 Figure 8: Trace element patterns in NWA 5790. A: Chondrite normalized

1342 REE pattern of the bulk of NWA 5790 compared to other nakhlites. The REE

1343 element abundances are the highest among nakhlites as expected from the

1344 high mesostasis fraction. Notice the similarity of the pattern with NWA 817, 
1345 Sautter et al. (2002). Data for Nakhla from Dreibus et al. (1982). B: Spider

1346 diagram normalized to Nakhla. The concentration of incompatible elements

1347 is controlled by the abundance of mesostasis. Note that the most

1348 incompatible elements exhibit a stronger enrichment in NWA 5790 indicating

1349 that the mesostasis of NWA 5790 is more differentiated than that of either

1350 NWA 817 or MIL 03346. Data for NWA 817 after Sautter et al. (2002)

1352 Figure 9: $\mathrm{Sr}$ vs $\mathrm{Al}_{2} \mathrm{O}_{3}$ abundance in nakhlites compared to shergottites,

1353 showing the different $\mathrm{Sr} / \mathrm{Al}_{2} \mathrm{O}_{3}$ ratios, which are significantly fractionated for

1354 nakhlites.

1355

1356 Figure 10: Chondrite normalized REE pattern of separate phases, as

1357 obtained by LA-ICP-MS. The bulk rock pattern (Fig. 8A) is clearly

1358 dominated by the mesostasis contribution. Note the absence of Eu anomaly

1359 in the mesostasis. The light REE in olivine of NWA 817 and MIL 03346 are

1360 affected by the presence of alteration (see text).

1361

1362

1363 Figure 11: The equilibrium between olivine and augite according to Toplis

1364 and Carroll (1995) corresponds to the thick plain line. It appears clearly that

1365 olivine and augite core compositions of some of the nakhlites are not in

1366 equilibrium (black squares; e.g. Lafayette). The red full circles correspond

1367 to adjacent crystals measured in NWA 817 by Sautter et al. (2002) and

1368 illustrate intercumulus closed system crystallization. Minor deviation from

1369 the equilibrium line may result from oscillatory zoning. Open circles/squares 
1370 for NWA 5790 pairs of olivine/augite crystals (intimate contact) illustrate a

1371 similar trend. $998=$ NWA 998, $\mathrm{Y}=\mathrm{Y}-000593 ; \mathrm{MIL}=\mathrm{MIL}$ 03346; $817=$

1372 NWA 817; GV = Governador Valadares.

1374 Figure 12: Equilibration temperature vs. Mg\# of melt, olivine and augite,

1375 derived from the experimental data of Toplis and Carroll (1995) (plain lines:

1376 best fit; fields: data dispersion). Outlined points are for contacting crystals in

1377 NWA 5790. The augite cores correspond to high temperatures of more

1378 magnesian melts, not in equilibrium with olivines derived from less mafic

1379 melts at a lower temperature. Crystals in the mesostasis appear to be in

1380 equilibrium. Data points from zoned rims in NWA 5790 suggest that

1381 overgrowths of olivine and augite may be in equilibrium. The dashed line

1382 separates cores from final overgrowth.

1384 Figure 13: False color chemical map of Fe:Ti: P (pink :orange and blue);

1385 showing olivine (pink) augite (crimson) and Ti-magnetite (orange). The $\mathrm{P}$

1386 rimming (blue) of both olivine and augite appears clearly. Detail from figure

$13871 \mathrm{~b}$, at left. Scale bar is one hundred micrometers. The preservation of

1388 chemical profiles in glass rimming crystals is unusual, as it requires very

1389 rapid cooling.

1390

1391 Figure 14: The nakhlite pile revisited. The different compositions of augite

1392 and olivine cores suggest that there are at least three distinct lavas flows.

1393 The textural and compositional kinship supports one common pile. NWA

13945790 despite of its top-of-pile characteristics is placed at the bottom 
1395 because of the absence of pervasive low temperature alteration. It is

1396 interpreted as the top of the deepest flow sampled so far. Modified after

1397 Mikouchi et al. (2003). 


\section{TABLES}

Table 1 : Magnetic properties of nakhlites

\begin{tabular}{|c|c|c|c|c|c|c|c|c|}
\hline Meteorite & $\mathrm{Pf}$ & $\mathrm{T}$ & $\begin{array}{c}\log \chi \\
10^{-9} \mathrm{~m}^{3} / \mathrm{kg}\end{array}$ & $\%$ para & $\begin{array}{c}\mathrm{Ms} \\
\mathbf{A m}^{2} / \mathbf{k g}\end{array}$ & $n$ & $\begin{array}{c}\text { mass } \\
\mathrm{g}\end{array}$ & ref \\
\hline $\begin{array}{l}\text { Governador } \\
\text { Valadares }\end{array}$ & 1.022 & 0.27 & 3.19 & 33.7 & 0.28 & 3 & 6.70 & $b, d$ \\
\hline Lafayette & 1.040 & & 3.32 & 20.1 & 0.22 & 3 & 3.50 & $d$ \\
\hline MIL03346 & 1.020 & 0.33 & 3.75 & 8.4 & 1.24 & 2 & 2.56 & $a, c$ \\
\hline Nakhla & 1.019 & 0.70 & 3.18 & 28.0 & 0.26 & 2 & 57.77 & $b$ \\
\hline NWA 5790 & 1.005 & 0.52 & 3.81 & 6.2 & 1.19 & 1 & 1.16 & $\mathrm{a}$ \\
\hline NWA 817 & 1.019 & -0.19 & 3.71 & 16.3 & 0.49 & 1 & 2.41 & $a$ \\
\hline NWA 998 & 1.031 & 0.31 & 3.60 & 10.7 & 0.71 & 2 & 1.71 & c \\
\hline Yamato $000593^{*}$ & 1.027 & 0.30 & 3.56 & 14.1 & 0.66 & 4 & 1.34 & $\mathrm{a}$ \\
\hline
\end{tabular}

$\%$ para $=$ contribution of paramagnetic susceptibility to total susceptibility. References: $a=$ this study; $b=$ Gattacceca et al., (2008); $c=$ Gattacceca et al., (2005); $d=$ Collinson, (1997).

* Yamato 000593 has a different magnetic mineralogy compared to other nakhlites as it contains pyrrhottite in addition to titanomagnetite (Funaki et al., 2002). 
Table 2: Representative analyses of augites

\begin{tabular}{|c|c|c|c|c|c|c|c|c|c|c|c|}
\hline \multirow[b]{2}{*}{$\mathrm{SiO}_{2}$} & \multirow[b]{2}{*}{50.77} & \multirow[b]{2}{*}{51.10} & \multirow[b]{2}{*}{50.83} & \multirow{2}{*}{$\begin{array}{l}\begin{array}{l}\text { core1 } \\
\text { mean }\end{array} \\
51.19\end{array}$} & \multirow{2}{*}{$\begin{array}{r}\begin{array}{l}\text { core2 } \\
\text { mean }\end{array} \\
50.68\end{array}$} & \multicolumn{3}{|l|}{ rim } & \multicolumn{3}{|c|}{ Mesostasis } \\
\hline & & & & & & 49.36 & 47.75 & 45.96 & 45.28 & 45.79 & 46.72 \\
\hline $\mathrm{TiO}_{2}$ & 0.42 & 0.24 & 0.53 & 0.27 & 0.43 & 0.68 & 0.91 & 0.91 & 0.77 & 0.52 & 0.12 \\
\hline $\mathrm{Al}_{2} \mathrm{O}_{3}$ & 1.03 & 0.86 & 1.34 & 0.85 & 1.29 & 1.77 & 2.40 & 3.10 & 2.49 & 0.86 & 1.89 \\
\hline $\mathrm{Cr}_{2} \mathrm{O}_{3}$ & 0.21 & 0.33 & 0.18 & 0.32 & 0.21 & 0.06 & 0.02 & 0.06 & 0.00 & 0.08 & 0.06 \\
\hline $\mathrm{MgO}$ & 11.32 & 11.99 & 10.47 & 12.04 & 10.68 & 9.45 & 7.93 & 5.61 & 5.51 & 4.11 & 1.32 \\
\hline $\mathrm{FeO}$ & 15.37 & 14.86 & 16.25 & 14.55 & 15.96 & 19.38 & 22.42 & 26.19 & 28.27 & 27.57 & 28.82 \\
\hline $\mathrm{MnO}$ & 0.47 & 0.43 & 0.49 & 0.43 & 0.45 & 0.51 & 0.64 & 0.63 & 0.72 & 0.62 & 0.54 \\
\hline $\mathrm{CaO}$ & 19.47 & 19.01 & 19.12 & 18.98 & 19.19 & 17.35 & 16.26 & 15.06 & 13.84 & 17.62 & 16.52 \\
\hline $\mathrm{Na}_{2} \mathrm{O}$ & 0.37 & 0.35 & 0.36 & 0.30 & 0.34 & 0.40 & 0.42 & 0.50 & 0.28 & 0.17 & 0.49 \\
\hline $\mathrm{K}_{2} \mathrm{O}$ & 0.03 & 0.02 & 0.00 & 0.00 & 0.01 & 0.00 & 0.01 & 0.04 & 0.02 & 0.09 & 0.31 \\
\hline Total & 99.48 & 99.28 & 99.66 & 99.00 & 99.29 & 98.96 & 98.77 & 98.10 & 97.22 & 97.53 & 96.87 \\
\hline Ti-Ts & 0.01 & 0.01 & 0.02 & 0.01 & 0.01 & 0.02 & 0.03 & 0.03 & 0.02 & 0.02 & 0.00 \\
\hline Al-Ts & 0.00 & 0.00 & -0.02 & 0.00 & 0.00 & 0.00 & 0.02 & 0.04 & 0.06 & 0.05 & 0.00 \\
\hline Jd & 0.03 & 0.03 & 0.03 & 0.02 & 0.03 & 0.03 & 0.03 & 0.04 & 0.02 & 0.01 & 0.04 \\
\hline En & 0.32 & 0.34 & 0.30 & 0.35 & 0.31 & 0.28 & 0.23 & 0.17 & 0.17 & 0.13 & 0.04 \\
\hline Fs & 0.24 & 0.23 & 0.26 & 0.23 & 0.25 & 0.31 & 0.36 & 0.43 & 0.43 & 0.40 & 0.49 \\
\hline Wo & 0.39 & 0.39 & 0.40 & 0.39 & 0.39 & 0.36 & 0.33 & 0.30 & 0.27 & 0.36 & 0.38 \\
\hline Mg\# & 57 & 59 & 53 & 60 & 54 & 47 & 39 & 28 & 26 & 21 & 8 \\
\hline $\mathrm{FeO} / \mathrm{MnO}$ & 33 & 35 & 33 & 34 & 36 & 38 & 35 & 41 & 39 & 44 & 54 \\
\hline
\end{tabular}


Table 3. Representative analyses of olivine

\begin{tabular}{|c|c|c|c|c|c|c|c|c|}
\hline & Core & & & & Rim & & & mesostasis \\
\hline $\mathrm{SiO}_{2}$ & 32.68 & 32.25 & 32.63 & 33.29 & 31.66 & 31.79 & 32.42 & 29.93 \\
\hline $\mathrm{TiO}_{2}$ & 0.01 & 0.02 & 0.04 & 0.03 & - & - & - & 0.12 \\
\hline $\mathrm{Al}_{2} \mathrm{O}_{3}$ & bdl & 0.04 & bdl & bdl & 0.11 & 0.02 & 0.02 & 0.1 \\
\hline $\mathrm{Cr}_{2} \mathrm{O}_{3}$ & bdl & 0.03 & 0.06 & 0.03 & 0.00 & -0.01 & 0.01 & bdl \\
\hline $\mathrm{MgO}$ & 14.84 & 15.47 & 14.79 & 14.59 & 4.53 & 8.30 & 11.80 & 2.65 \\
\hline $\mathrm{FeO}$ & 49.83 & 48.99 & 49.89 & 49.52 & 61.08 & 58.24 & 53.89 & 64.43 \\
\hline $\mathrm{MnO}$ & 1.18 & 1.08 & 1.09 & 1.06 & 1.45 & 1.22 & 1.17 & 1.64 \\
\hline $\mathrm{CaO}$ & 0.53 & 0.56 & 0.54 & 0.56 & 0.32 & 0.38 & 0.48 & 0.18 \\
\hline $\mathrm{P}_{2} \mathrm{O}_{5}$ & 0.02 & 0.04 & 0.03 & 0.03 & 0.07 & 0.08 & 0.07 & 0.35 \\
\hline Total & 99.14 & 98.51 & 99.13 & 99.11 & 99.03 & 99.94 & 99.76 & 99.45 \\
\hline Mg\# & 35 & 36 & 35 & 34 & 12 & 20 & 28 & 7 \\
\hline $\mathrm{FeO} / \mathrm{MnO}$ & 42 & 46 & 46 & 47 & 42 & 48 & 46 & 39 \\
\hline
\end{tabular}

bdl: below detection limit 
Table 4: Representative analyses of silicates in the mesostasis.

\begin{tabular}{lrrrr}
\hline & plagioclase & & K-spar & silica \\
$\mathrm{SiO}_{2}$ & 64.31 & 66.86 & 64.51 & 100.50 \\
$\mathrm{TiO}_{2}$ & 0.04 & 0.34 & - & 0.01 \\
$\mathrm{Al}_{2} \mathrm{O}_{3}$ & 21.65 & 16.77 & 18.54 & 0.19 \\
$\mathrm{Cr}_{2} \mathrm{O}_{3}$ & \multicolumn{1}{c}{} & 0.03 & 0.02 & - \\
$\mathrm{MgO}$ & 0.02 & 0.15 & - & - \\
$\mathrm{FeO}$ & 0.74 & 2.40 & 0.64 & 0.50 \\
$\mathrm{MnO}$ & - & 0.10 & 0.02 & - \\
$\mathrm{CaO}$ & 3.16 & 2.99 & 0.36 & 0.02 \\
$\mathrm{Na} O$ & 9.02 & 6.27 & 1.83 & 0.07 \\
$\mathrm{~K}_{2} \mathrm{O}$ & 1.14 & 1.70 & 13.36 & 0.05 \\
$\mathrm{P}_{2} \mathrm{O}_{5}$ & 0.05 & 0.56 & 0.06 & - \\
$\mathrm{Total}$ & 100.14 & 98.16 & 99.35 & 101.33 \\
& & & & \\
$\mathrm{Si}$ & 2.85 & 3.12 & 2.99 & \\
$\mathrm{Al}$ & 1.13 & 0.92 & 1.01 & \\
$\mathrm{Fe}$ & 0.03 & 0.09 & 0.02 & \\
$\mathrm{Ca}$ & 0.15 & 0.15 & 0.02 & \\
$\mathrm{Na}$ & 0.78 & 0.57 & 0.16 & \\
$\mathrm{~K}$ & 0.06 & 0.10 & 0.79 & \\
$\mathrm{An}$ & & & & \\
$\mathrm{Ab}$ & 0.15 & 0.18 & 0.02 & \\
$\mathrm{Or}$ & 0.78 & 0.69 & 0.17 & \\
\hline
\end{tabular}


Table 5: Nakhlites mesostase compositions compared, as measured in scanning mode.

\begin{tabular}{|c|c|c|c|c|c|c|}
\hline \multirow{3}{*}{$n$} & \multicolumn{2}{|c|}{ NWA 5790} & \multicolumn{2}{|c|}{ MIL 03346} & \multicolumn{2}{|c|}{ NWA 817} \\
\hline & 12 & & 13 & & $53 *$ & \\
\hline & mean & error & mean & error & mean & error \\
\hline $\mathrm{SiO}_{2}$ & 51.75 & 0.20 & 52.93 & 0.89 & 52.78 & 0.21 \\
\hline $\mathrm{TiO}_{2}$ & 1.03 & 0.01 & 0.82 & 0.14 & 0.82 & 0.02 \\
\hline $\mathrm{Al}_{2} \mathrm{O}_{3}$ & 13.19 & 0.09 & 13.96 & 0.31 & 14.51 & 0.07 \\
\hline $\mathrm{Cr}_{2} \mathrm{O}_{3}$ & 0.00 & 0.00 & 0.00 & 0.00 & 0.00 & 0.00 \\
\hline $\mathrm{MgO}$ & 0.58 & 0.01 & 0.42 & 0.04 & 0.82 & 0.02 \\
\hline $\mathrm{FeO}$ & 16.67 & 0.27 & 16.83 & 1.16 & 13.78 & 0.22 \\
\hline $\mathrm{MnO}$ & 0.32 & 0.01 & 0.24 & 0.02 & 0.27 & 0.01 \\
\hline $\mathrm{CaO}$ & 4.68 & 0.07 & 4.04 & 0.16 & 4.48 & 0.11 \\
\hline $\mathrm{Na}_{2} \mathrm{O}$ & 5.30 & 0.04 & 5.22 & 0.11 & 6.58 & 0.05 \\
\hline $\mathrm{K}_{2} \mathrm{O}$ & 1.62 & 0.02 & 1.06 & 0.05 & 2.10 & 0.03 \\
\hline $\mathrm{P}_{2} \mathrm{O}_{5}$ & 1.04 & 0.05 & 0.84 & 0.03 & 1.58 & 0.05 \\
\hline $\mathrm{SO}_{2}$ & - & & - & & 0.18 & 0.03 \\
\hline $\mathrm{Cl}$ & - & & - & & 0.11 & 0.00 \\
\hline Total & 96.18 & 0.07 & 96.35 & 0.27 & 98.01 & 0.20 \\
\hline $\mathrm{Mg} \#$ & 5.8 & & 4.3 & & 9.6 & \\
\hline
\end{tabular}

$\mathrm{n}$ is the number of scanned areas. Error is one standard deviation divided by $\mathrm{n}^{1 / 2}$.

* areas scanned are four times smaller. 
Table 6 : Representative analyses of alteration products in augite and olivine fractures compared to amphibiole from MIL 03346 (Sautter et al. 2006) and smectite in NWA 817 (Gillet et al. 2002) :

\begin{tabular}{|c|c|c|c|c|c|c|c|c|c|}
\hline \multirow{3}{*}{$\mathrm{n}$} & \multicolumn{2}{|l|}{ Low Al } & High Al & \multicolumn{3}{|c|}{ High Cl } & \multirow[t]{2}{*}{ MIL03346 } & \multirow{2}{*}{$\begin{array}{r}\text { NWA817 } \\
16\end{array}$} & \multirow{2}{*}{$\begin{array}{r}\text { NWA817 } \\
25\end{array}$} \\
\hline & 42 & 42 & 14 & 14 & 5 & 5 & & & \\
\hline & mean & sigma & mean & sigma & mean & sigma & $\begin{array}{l}\text { M Inc. } \\
\text { amphibole }\end{array}$ & $\begin{array}{l}\text { mesost. } \\
\text { smectite } \\
\text { mean }\end{array}$ & $\begin{array}{l}\text { olivine } \\
\text { smectite } \\
\text { mean }\end{array}$ \\
\hline $\mathrm{SiO}_{2}$ & 46.61 & 2.21 & 49.89 & 7.14 & 44.56 & 5.99 & 37.48 & 46.51 & 42.82 \\
\hline $\mathrm{TiO}_{2}$ & 0.53 & 0.23 & 0.42 & 0.52 & 0.77 & 0.76 & 0.38 & 0.03 & 0.06 \\
\hline $\mathrm{Al}_{2} \mathrm{O}_{3}$ & 2.42 & 1.31 & 15.08 & 3.42 & 13.43 & 2.43 & 8.62 & 2.26 & 0.21 \\
\hline $\mathrm{MgO}$ & 7.92 & 2.08 & 0.89 & 0.59 & 0.83 & 0.18 & 0.97 & 7.56 & 5.69 \\
\hline $\mathrm{FeO}$ & 18.69 & 3.30 & 12.18 & 6.92 & 18.10 & 5.46 & 31.95 & 28.42 & 36.45 \\
\hline $\mathrm{MnO}$ & 0.49 & 0.10 & 0.19 & 0.13 & 0.19 & 0.07 & 0.36 & 0.28 & 0.55 \\
\hline $\mathrm{CaO}$ & 16.79 & 1.55 & 7.71 & 3.08 & 7.96 & 1.13 & 9.23 & 0.14 & 0.25 \\
\hline $\mathrm{Na}_{2} \mathrm{O}$ & 0.43 & 0.26 & 3.55 & 1.41 & 2.85 & 1.28 & 0.76 & 0.06 & 0.18 \\
\hline $\mathrm{K}_{2} \mathrm{O}$ & 0.16 & 0.21 & 2.25 & 1.50 & 2.46 & 1.02 & 2.52 & 0.42 & 0.41 \\
\hline $\mathrm{P}_{2} \mathrm{O}_{5}$ & 0.37 & 0.44 & 1.37 & 1.54 & 0.91 & 1.13 & 0.18 & - & - \\
\hline $\mathrm{Cl}$ & 0.21 & 0.48 & 1.31 & 1.26 & 2.74 & 0.75 & 5.01 & - & - \\
\hline Total & 94.74 & 1.18 & 94.88 & 2.93 & 94.86 & 4.97 & 97.78 & 85.68 & 86.65 \\
\hline Mg\# & 0.43 & & 0.11 & & 0.08 & & 0.05 & 0.32 & 0.22 \\
\hline Si & 7.21 & 0.20 & 7.11 & 0.54 & 6.66 & 0.39 & 5.97 & 7.37 & 7.04 \\
\hline Ti & 0.06 & 0.03 & 0.04 & 0.06 & 0.09 & 0.09 & 0.05 & 0.00 & 0.01 \\
\hline $\mathrm{Al}$ & 0.45 & 0.25 & 2.53 & 0.47 & 2.36 & 0.37 & 1.62 & 0.42 & 0.04 \\
\hline $\mathrm{Mg}$ & 1.82 & 0.45 & 0.19 & 0.13 & 0.18 & 0.05 & 0.23 & 1.79 & 1.39 \\
\hline $\mathrm{Fe}$ & 2.43 & 0.48 & 1.45 & 0.92 & 2.26 & 0.79 & 4.25 & 3.77 & 5.01 \\
\hline $\mathrm{Mn}$ & 0.06 & 0.01 & 0.02 & 0.02 & 0.02 & 0.01 & 0.05 & 0.04 & 0.08 \\
\hline $\mathrm{Ca}$ & 2.78 & 0.21 & 1.18 & 0.53 & 1.28 & 0.24 & 1.58 & 0.02 & 0.04 \\
\hline $\mathrm{Na}$ & 0.13 & 0.08 & 0.98 & 0.34 & 0.83 & 0.32 & 0.23 & 0.02 & 0.06 \\
\hline K & 0.03 & 0.04 & 0.41 & 0.26 & 0.47 & 0.16 & 0.51 & 0.09 & 0.09 \\
\hline
\end{tabular}


$\begin{array}{cccccccc}\mathrm{Cl} & 0.06 & 0.13 & 0.32 & 0.33 & 0.69 & 0.23 & 1.35\end{array}$ 
Table 7: Representative analyses of oxides.

\begin{tabular}{|c|c|c|c|c|c|c|c|c|}
\hline \multirow[b]{2}{*}{$\mathrm{SiO}_{2}$} & \multicolumn{3}{|c|}{ Phenocrysts } & \multicolumn{5}{|c|}{ Mesostasis } \\
\hline & 0.16 & 0.09 & 0.08 & 0.11 & 0.64 & 0.87 & 0.21 & 1.68 \\
\hline $\mathrm{TiO}_{2}$ & 10.32 & 10.94 & 12.11 & 11.12 & 19.63 & 20.83 & 22.38 & 24.73 \\
\hline $\mathrm{Al}_{2} \mathrm{O}_{3}$ & 2.96 & 3.04 & 2.71 & 2.90 & 0.30 & 0.38 & 0.33 & 0.62 \\
\hline $\mathrm{Cr}_{2} \mathrm{O}_{3}$ & 1.34 & 2.90 & 2.61 & 2.28 & 0.05 & 0.00 & 0.01 & 0.03 \\
\hline $\mathrm{MgO}$ & 0.13 & 0.46 & 0.50 & 0.36 & 0.11 & 0.06 & 0.07 & 0.07 \\
\hline $\mathrm{FeO}$ & 74.95 & 74.88 & 74.04 & 74.62 & 69.89 & 67.58 & 67.88 & 63.20 \\
\hline $\mathrm{MnO}$ & 0.36 & 0.29 & 0.47 & 0.37 & 0.41 & 0.50 & 0.35 & 0.42 \\
\hline $\mathrm{CaO}$ & 0.01 & 0.02 & 0.03 & 0.02 & 0.13 & 0.12 & 0.15 & 0.21 \\
\hline $\mathrm{Na}_{2} \mathrm{O}$ & - & - & 0.02 & - & 0.05 & 0.00 & - & 0.17 \\
\hline $\mathrm{K}_{2} \mathrm{O}$ & 0.01 & 0.00 & 0.01 & 0.01 & 0.04 & 0.04 & 0.01 & 0.09 \\
\hline $\mathrm{SO}_{2}$ & 0.01 & 0.00 & 0.01 & 0.00 & 0.03 & 0.00 & 0.00 & 0.07 \\
\hline $\mathrm{P}_{2} \mathrm{O}_{5}$ & - & 0.01 & - & 0.00 & 0.00 & - & - & 0.04 \\
\hline $\mathrm{NiO}$ & - & 0.02 & 0.04 & 0.02 & 0.00 & - & - & 0.03 \\
\hline Total & 90.24 & 92.63 & 92.64 & 91.84 & 91.27 & 90.37 & 91.39 & 91.36 \\
\hline $\mathrm{Si}$ & 0.01 & 0.00 & 0.00 & & 0.03 & 0.04 & 0.01 & 0.07 \\
\hline $\mathrm{Ti}$ & 0.31 & 0.32 & 0.35 & & 0.59 & 0.63 & 0.67 & 0.74 \\
\hline $\mathrm{Al}$ & 0.14 & 0.14 & 0.12 & & 0.01 & 0.02 & 0.02 & 0.03 \\
\hline $\mathrm{Cr}$ & 0.04 & 0.09 & 0.08 & & 0.00 & 0.00 & 0.00 & 0.00 \\
\hline $\mathrm{Mg}$ & 0.01 & 0.03 & 0.03 & & 0.01 & 0.00 & 0.00 & 0.00 \\
\hline $\mathrm{Fe}$ & 2.49 & 2.42 & 2.39 & & 2.34 & 2.29 & 2.28 & 2.11 \\
\hline $\mathrm{Mn}$ & 0.01 & 0.01 & 0.02 & & 0.01 & 0.02 & 0.01 & 0.01 \\
\hline $\mathrm{Fe}^{3+}$ & 1.19 & 1.13 & 1.09 & & 0.77 & 0.65 & 0.62 & 0.38 \\
\hline $\mathrm{Fe}^{2+}$ & 1.30 & 1.29 & 1.30 & & 1.57 & 1.64 & 1.66 & 1.73 \\
\hline
\end{tabular}




\begin{tabular}{lccccccc}
$\mathrm{Fe}^{3+/ \mathrm{Fe}}$ & 0.48 & 0.47 & 0.46 & 0.33 & 0.28 & 0.27 & 0.18 \\
& & & & & & & \\
Ulvöspinel & 0.31 & 0.32 & 0.35 & 0.59 & 0.63 & 0.67 & 0.74 \\
Magnetite & 0.59 & 0.56 & 0.55 & 0.38 & 0.33 & 0.31 & 0.19 \\
Chromite & 0.02 & 0.04 & 0.04 & 0.00 & 0.00 & 0.00 & 0.00 \\
Spinel & 0.07 & 0.07 & 0.06 & 0.01 & 0.01 & 0.01 & 0.01 \\
\hline
\end{tabular}


Table 8 : Major (wt \%) and trace (ppm) element composition of NWA 5790 and other nakhlites

\begin{tabular}{|c|c|c|c|c|}
\hline & $\begin{array}{l}\text { NWA } \\
5790\end{array}$ & $\begin{array}{r}\text { MIL } \\
03346\end{array}$ & $\begin{array}{r}\text { NWA } \\
817\end{array}$ & Nakhla \\
\hline & $a$ & $a$ & $b$ & $c, d$ \\
\hline $\mathrm{SiO}_{2}$ & - & - & - & 49.33 \\
\hline $\mathrm{TiO}_{2}$ & 0.57 & 0.69 & 0.61 & 0.35 \\
\hline $\mathrm{Al}_{2} \mathrm{O}_{3}$ & 5.19 & 3.66 & 3.28 & 1.64 \\
\hline $\mathrm{Cr}_{2} \mathrm{O}_{3}$ & 0.11 & - & 0.22 & 0.25 \\
\hline $\mathrm{MgO}$ & 7.79 & 9.99 & 10.31 & 11.82 \\
\hline $\mathrm{FeO}$ & 17.79 & 19.12 & 19.84 & 21.70 \\
\hline $\mathrm{MnO}$ & 0.47 & 0.46 & 0.53 & 0.55 \\
\hline $\mathrm{CaO}$ & 12.93 & 15.75 & 13.07 & 14.30 \\
\hline $\mathrm{Na}_{2} \mathrm{O}$ & 2.02 & 1.00 & 0.94 & 0.57 \\
\hline $\mathrm{K}_{2} \mathrm{O}$ & 0.52 & 0.27 & 0.32 & 0.17 \\
\hline $\mathrm{P}_{2} \mathrm{O}_{5}$ & 0.37 & 0.25 & - & 0.10 \\
\hline Total & $(47.76)$ & $(51.19)$ & $(49.12)$ & 100.78 \\
\hline Mg\# & 44 & 48 & 48 & 49 \\
\hline $\mathrm{Li}$ & 6.95 & 4.25 & 7.43 & 3.80 \\
\hline $\mathrm{Be}$ & 0.60 & 0.30 & 0.44 & - \\
\hline Sc & 49.9 & 54.5 & 47.0 & 55.0 \\
\hline V & 243 & 208 & 181 & 192 \\
\hline $\mathrm{Cr}$ & 769 & 1192 & 1519 & 1710 \\
\hline Co & 38.5 & 35.7 & 49.0 & 54.0 \\
\hline $\mathrm{Ni}$ & 41.0 & 49 & 71.0 & 90.0 \\
\hline $\mathrm{Cu}$ & 16.24 & 8.2 & 12.70 & 6.70 \\
\hline $\mathrm{Zn}$ & 90.73 & 61.3 & 71.52 & 70.0 \\
\hline $\mathrm{Ga}$ & 9.57 & 6.51 & 6.77 & 3.70 \\
\hline $\mathrm{Rb}$ & 7.39 & 4.14 & 6.06 & 3.15 \\
\hline $\mathrm{Sr}$ & 210.6 & 132.0 & 145.0 & 75.0 \\
\hline Y & 13.76 & 8.44 & 9.86 & - \\
\hline $\mathrm{Zr}$ & 41.01 & 21.58 & 29.72 & - \\
\hline $\mathrm{Nb}$ & 7.94 & 3.47 & 4.60 & - \\
\hline
\end{tabular}




\begin{tabular}{lrrrr} 
Mo & 0.03 & - & 0.17 & - \\
$\mathrm{Cs}$ & 0.11 & 0.25 & 0.25 & 0.43 \\
$\mathrm{Ba}$ & 285.4 & 59.58 & 167.0 & 34.0 \\
$\mathrm{La}$ & 9.10 & 4.70 & 5.92 & 2.14 \\
$\mathrm{Ce}$ & 22.31 & 11.01 & 14.70 & 5.60 \\
$\mathrm{Pr}$ & 3.10 & 1.56 & 2.11 & - \\
$\mathrm{Nd}$ & 13.52 & 7.07 & 9.02 & 2.85 \\
$\mathrm{Sm}$ & 2.87 & 1.64 & 1.97 & 0.78 \\
$\mathrm{Eu}$ & 0.83 & 0.522 & 0.58 & 0.23 \\
$\mathrm{Gd}$ & 2.82 & 1.73 & 1.96 & - \\
$\mathrm{Tb}$ & 0.43 & 0.266 & 0.31 & 0.13 \\
$\mathrm{Dy}$ & 2.53 & 1.57 & 1.81 & - \\
$\mathrm{Ho}$ & 0.50 & 0.317 & 0.36 & 0.17 \\
$\mathrm{Er}$ & 1.34 & 0.851 & 0.95 & - \\
$\mathrm{Yb}$ & 1.15 & 0.766 & 0.82 & 0.40 \\
$\mathrm{Lu}$ & 0.16 & 0.114 & 0.12 & 0.06 \\
$\mathrm{Hf}$ & 1.17 & 0.72 & 0.78 & 0.29 \\
$\mathrm{Ta}$ & 0.51 & 0.20 & 0.25 & 0.09 \\
$\mathrm{~W}$ & 0.80 & 0.33 & 0.45 & 0.18 \\
$\mathrm{~Pb}$ & 2.82 & 0.91 & 1.90 & 0.51 \\
$\mathrm{Th}$ & 0.85 & 0.42 & 0.60 & 0.24 \\
$\mathrm{U}$ & 0.22 & 0.09 & 0.14 & 0.056 \\
\hline
\end{tabular}

a: this work, b: Sautter et al. (2002), c: Dreibus et al. (1982), d: Nakamura et al. (1982) 
Table 9: Trace element compositions of separate minerals in NWA 5790 as obtained by LA-ICP-MS.

\begin{tabular}{|c|c|c|c|c|c|c|c|c|c|}
\hline & $\begin{array}{r}\text { NWA } 817 \\
\text { augite } \\
\text { mean }\end{array}$ & $\begin{array}{r}\text { MIL03346 } \\
\text { augite } \\
\text { mean }\end{array}$ & $\begin{array}{c}\text { NWA5790 } \\
\text { augite } \\
\text { mean }\end{array}$ & $\begin{array}{r}\text { NWA817 } \\
\text { Olivine } \\
\text { mean }\end{array}$ & $\begin{array}{r}\text { MIL03346 } \\
\text { Olivine } \\
\text { mean }\end{array}$ & $\begin{array}{c}\text { NWA5790 } \\
\text { Olivine } \\
\text { mean }\end{array}$ & $\begin{array}{r}\text { NWA817 } \\
\text { Mesostase } \\
\text { mean }\end{array}$ & $\begin{array}{r}\text { MIL03346 } \\
\text { Mesostase } \\
\text { mean }\end{array}$ & $\begin{array}{r}\text { NWA5790 } \\
\text { Mesostase } \\
\text { mean }\end{array}$ \\
\hline $\mathrm{n}$ & 8 & 13 & 7 & 2 & 2 & 1 & 3 & 2 & 2 \\
\hline $\mathrm{Ti}$ & 1823 & 1711 & 2200 & 119 & 121 & 269.19 & - & 4949 & 5330 \\
\hline Co & 35.9 & 37.5 & 42.5 & 103.7 & 124 & 171.1 & - & 8.9 & 11.6 \\
\hline $\mathrm{Ni}$ & 63.7 & 63.2 & 57.4 & 173.8 & 195 & 224.6 & - & 1.8 & 3.3 \\
\hline $\mathrm{Rb}$ & & & & & & & 24.47 & 11.88 & 14.66 \\
\hline $\mathrm{Sr}$ & 39.0 & 33.2 & 38.8 & 2.12 & 0.25 & - & 541 & 481 & 282.3 \\
\hline $\mathrm{Y}$ & 5.00 & 4.68 & 5.34 & 0.35 & 0.73 & - & 25.8 & 23.2 & 14.1 \\
\hline $\mathrm{Zr}$ & 3.94 & 3.53 & 9.19 & 0.41 & - & - & 118 & 98 & 63.6 \\
\hline $\mathrm{Ba}$ & 8.44 & 1.96 & 9.25 & 4.30 & - & - & 490 & 273 & 422 \\
\hline $\mathrm{La}$ & 0.68 & 0.58 & 0.64 & 0.08 & 0.208 & 0.012 & 22.00 & 17.36 & 13.16 \\
\hline $\mathrm{Ce}$ & 2.61 & 2.28 & 2.84 & 0.16 & 0.402 & 0.014 & 51.39 & 41.85 & 33.66 \\
\hline $\operatorname{Pr}$ & 0.50 & 0.45 & 0.56 & 0.02 & 0.120 & 0.004 & 6.62 & 6.13 & 4.19 \\
\hline $\mathrm{Nd}$ & 2.97 & 2.74 & 3.34 & 0.07 & 0.635 & 0.021 & 29.71 & 28.34 & 17.90 \\
\hline Sm & 0.90 & 0.83 & 1.05 & 0.02 & 0.120 & 0.013 & 5.87 & 5.81 & 3.51 \\
\hline Eu & 0.26 & 0.23 & 0.32 & 0.00 & 0.022 & 0.012 & 1.63 & 1.75 & 1.02 \\
\hline Gd & 1.01 & 0.93 & 1.10 & 0.02 & 0.113 & 0.025 & 5.15 & 5.02 & 2.89 \\
\hline Dy & 1.01 & 0.94 & 1.08 & 0.04 & 0.118 & 0.041 & 4.89 & 4.66 & 2.64 \\
\hline Er & 0.53 & 0.49 & 0.56 & 0.05 & 0.097 & 0.044 & 2.64 & 2.55 & 1.44 \\
\hline $\mathrm{Yb}$ & 0.46 & 0.44 & 0.52 & 0.09 & 0.127 & 0.082 & 2.32 & 2.38 & 1.28 \\
\hline Lu & 0.07 & 0.07 & 0.08 & 0.02 & 0.023 & 0.015 & 0.32 & 0.35 & 0.18 \\
\hline $\mathrm{Hf}$ & 0.18 & 0.15 & 0.21 & 0.01 & - & - & 2.83 & 2.74 & 1.62 \\
\hline Th & - & - & - & - & - & - & 2.53 & 2.24 & 1.44 \\
\hline U & - & - & - & - & - & - & 0.57 & 0.60 & 0.38 \\
\hline
\end{tabular}


Table 10: Parent magma compositions

\begin{tabular}{lrrrrrrrrr}
\hline & $\mathrm{J} 1$ & $\mathrm{~J} 2$ & $\mathrm{J3}$ & $\mathrm{J} 4$ & $\mathrm{NK01}$ & $\mathrm{S} 04$ & $\mathrm{~N}$ & $\mathrm{GH}(6)$ & $\mathrm{D}$ \\
\hline $\mathrm{SiO}_{2}$ & 52.54 & 52.33 & 52.40 & 52.12 & 49.8 & 51.2 & 49.01 & 55.4 & 45.13 \\
$\mathrm{TiO}_{2}$ & 0.97 & 0.93 & 0.98 & 0.85 & 0.8 & 0.84 & 1.06 & 1.07 & 0.59 \\
$\mathrm{Al}_{2} \mathrm{O}_{3}$ & 11.69 & 11.03 & 11.68 & 9.24 & 7.5 & 7.1 & 2.85 & 9.4 & 3.39 \\
$\mathrm{Cr}_{2} \mathrm{O}_{3}$ & 0.02 & 0.03 & 0.01 & 0.04 & 0.1 & nd & 0.08 & nd & 0.31 \\
$\mathrm{MgO}$ & 1.72 & 2.32 & 1.70 & 4.39 & 4.6 & 4.6 & 5.22 & 4.9 & 12.06 \\
$\mathrm{FeO}$ & 18.71 & 18.81 & 19.09 & 17.98 & 22.3 & 19.6 & 26.23 & 13.4 & 26.84 \\
$\mathrm{MnO}$ & 0.36 & 0.36 & 0.36 & 0.35 & 0.5 & 0.53 & 0.73 & 0.24 & 0.88 \\
$\mathrm{CaO}$ & 6.70 & 7.38 & 6.64 & 9.54 & 10.4 & 11.2 & 13.92 & 10.2 & 10.57 \\
$\mathrm{Na}_{2} \mathrm{O}$ & 4.61 & 4.31 & 4.57 & 3.50 & 1.1 & 2.1 & 0.97 & 3.2 & 0.86 \\
$\mathrm{~K}_{2} \mathrm{O}$ & 1.40 & 1.30 & 1.38 & 1.04 & 2.4 & 0.7 & 0.2 & 0.6 & 0.34 \\
$\mathrm{P}_{2} \mathrm{O}_{5}$ & 0.90 & 0.84 & 0.89 & 0.67 & 0.6 & 0.97 & $\mathrm{nd}$ & $\mathrm{nd}$ & $\mathrm{nd}$ \\
$\mathrm{Total}$ & 99.63 & 99.65 & 99.69 & 99.72 & 100.1 & 98.84 & 100.27 & 98.41 & 100.97 \\
\hline $\mathrm{Mg} \#$ & 14.1 & 18.0 & 13.7 & 30.4 & 27.0 & 29.6 & 26.2 & 33.3 & 44.5
\end{tabular}

J1-4 this work NWA 5790 : J1 before adcumulus growth, J2 before crystallization of Augite+olivine phenocrysts, $\mathrm{J} 3$ before dissolution of $6 \%$ of olivine xenocrysts, 34 melt in equilibrium with NWA 817 augite core.

NK01 Treiman and Goodrich (2001), S04: Stockstill et al. (2005), GH(6): Varela et al. (2001), N

Longhi and Pan (1989), D Treiman (1986) 


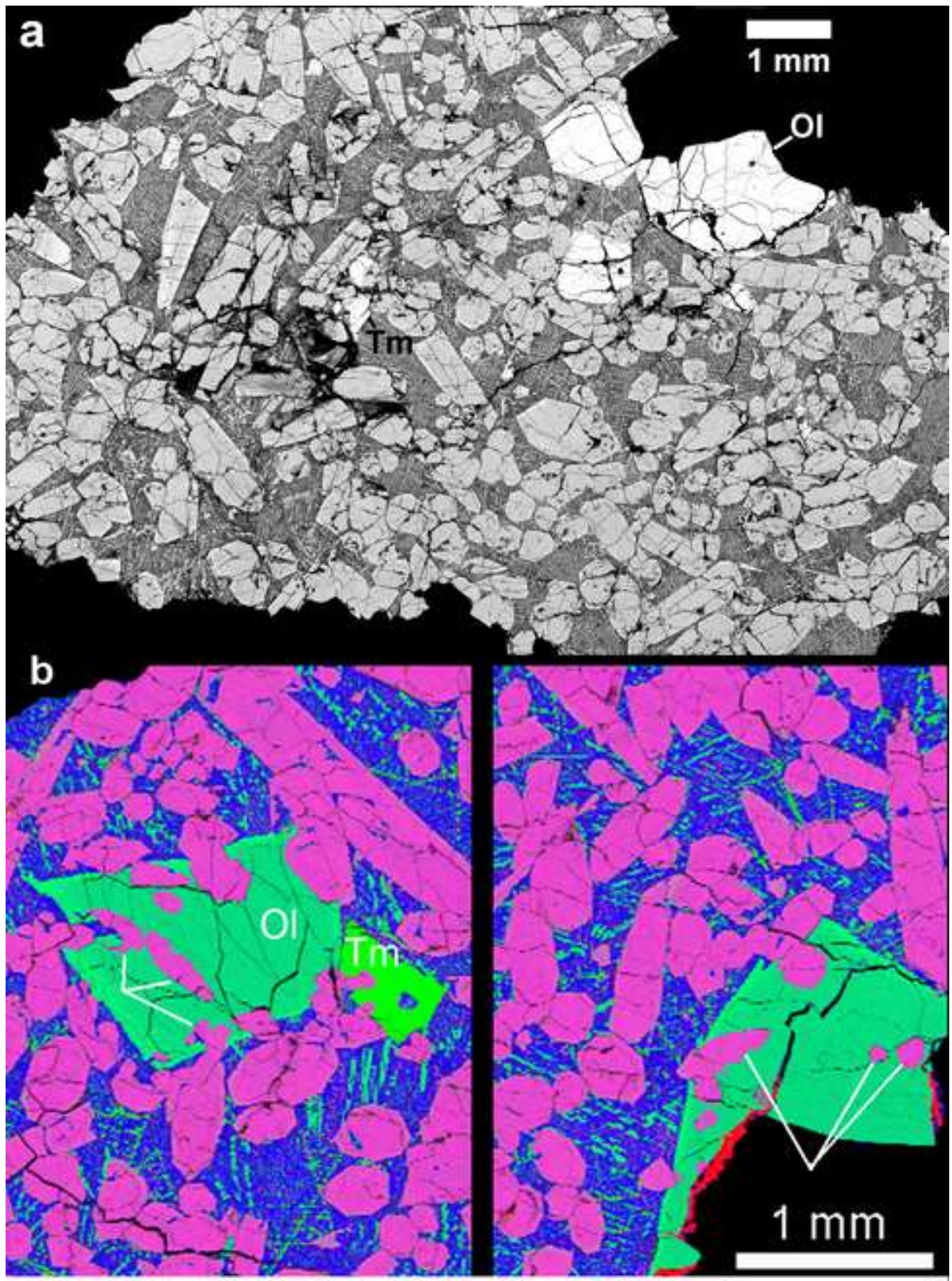

Figure 1. Jambon et al. 

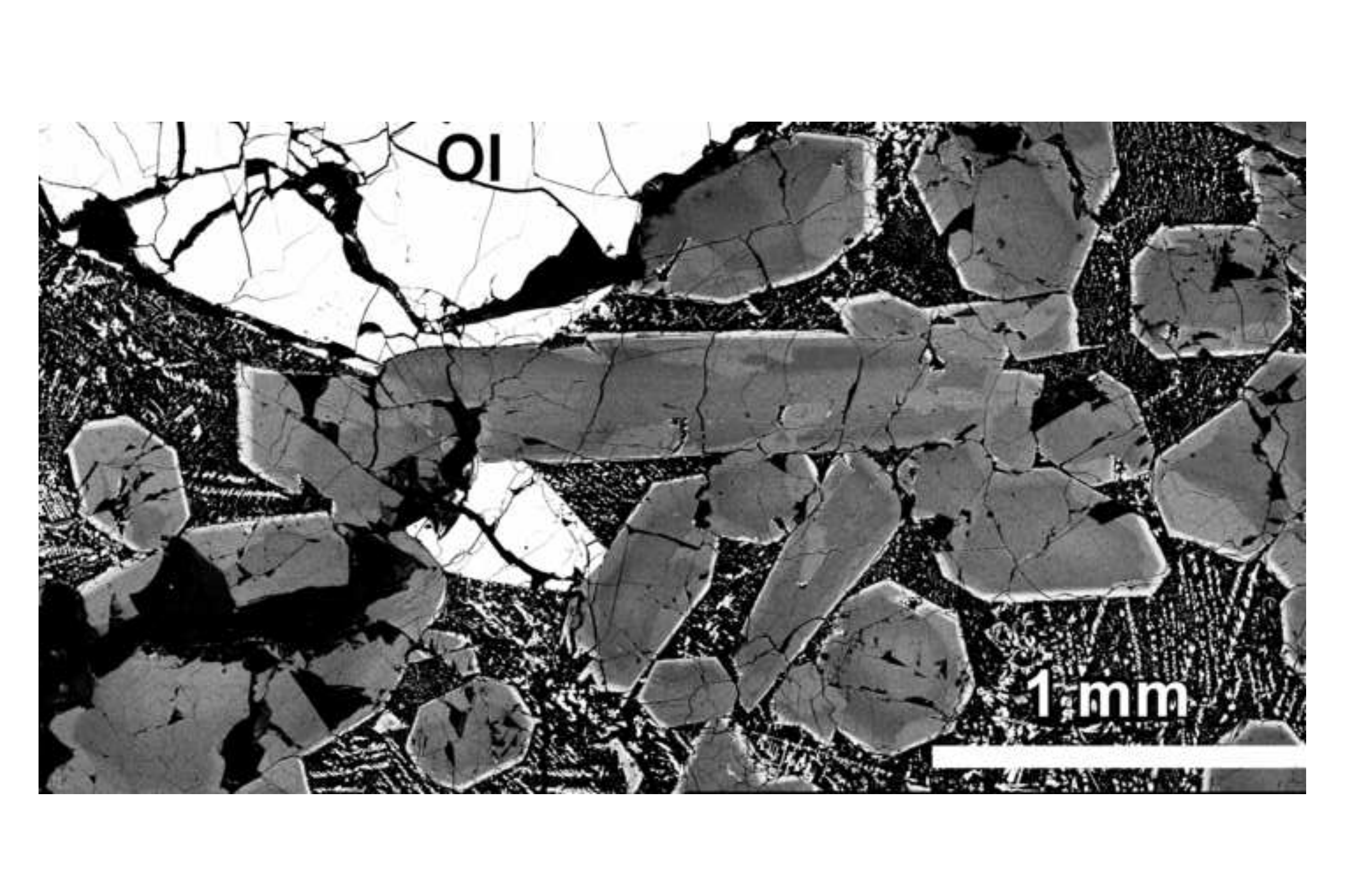
$\diamond$ core

- rim mesostasis

$\bigcirc$ MIL 03346

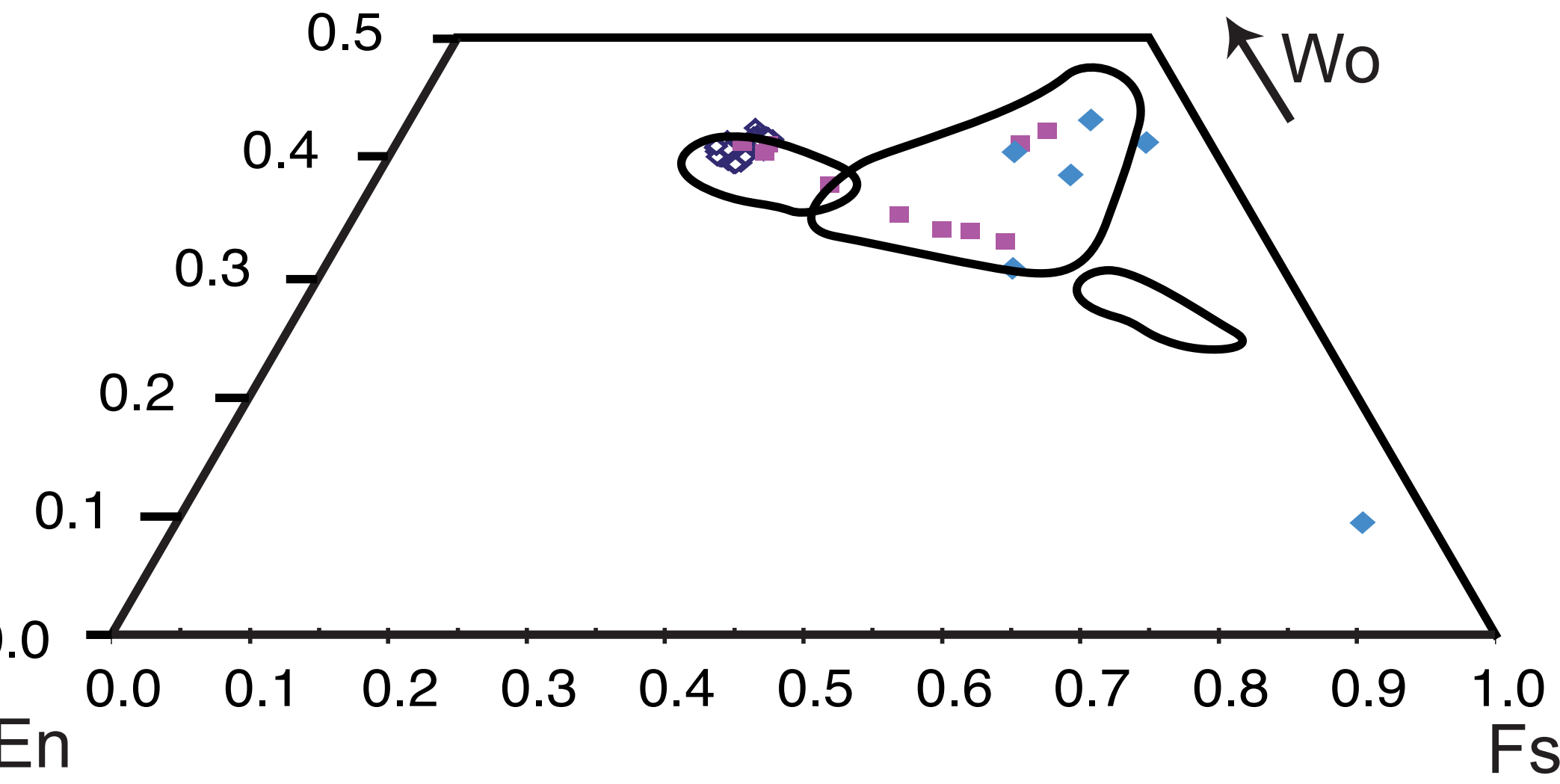

Figure 4. Jambon et al. 


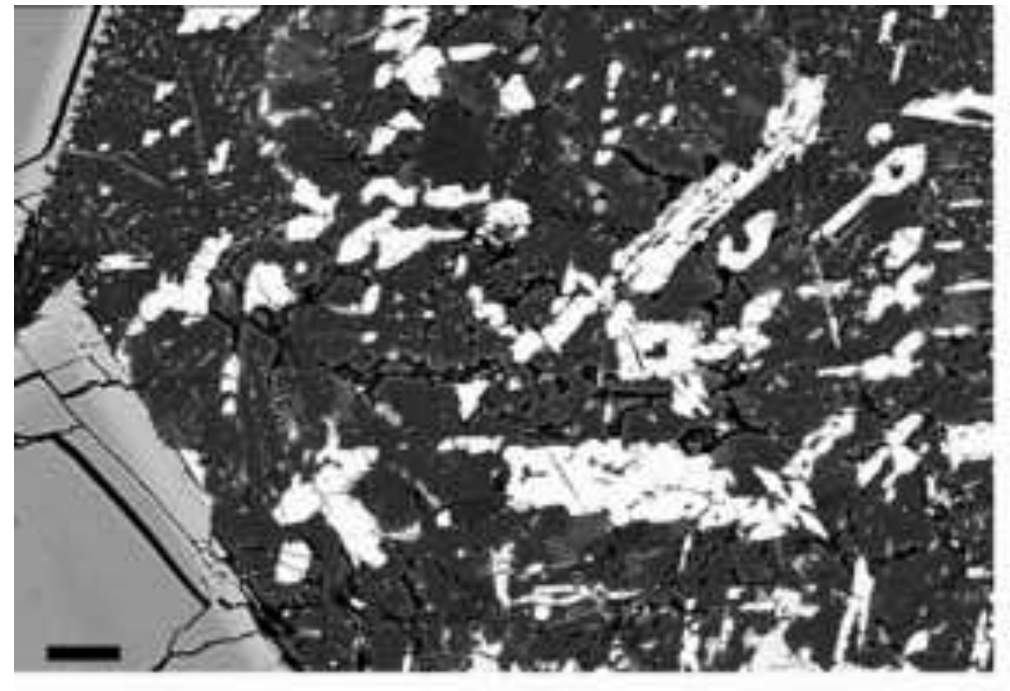
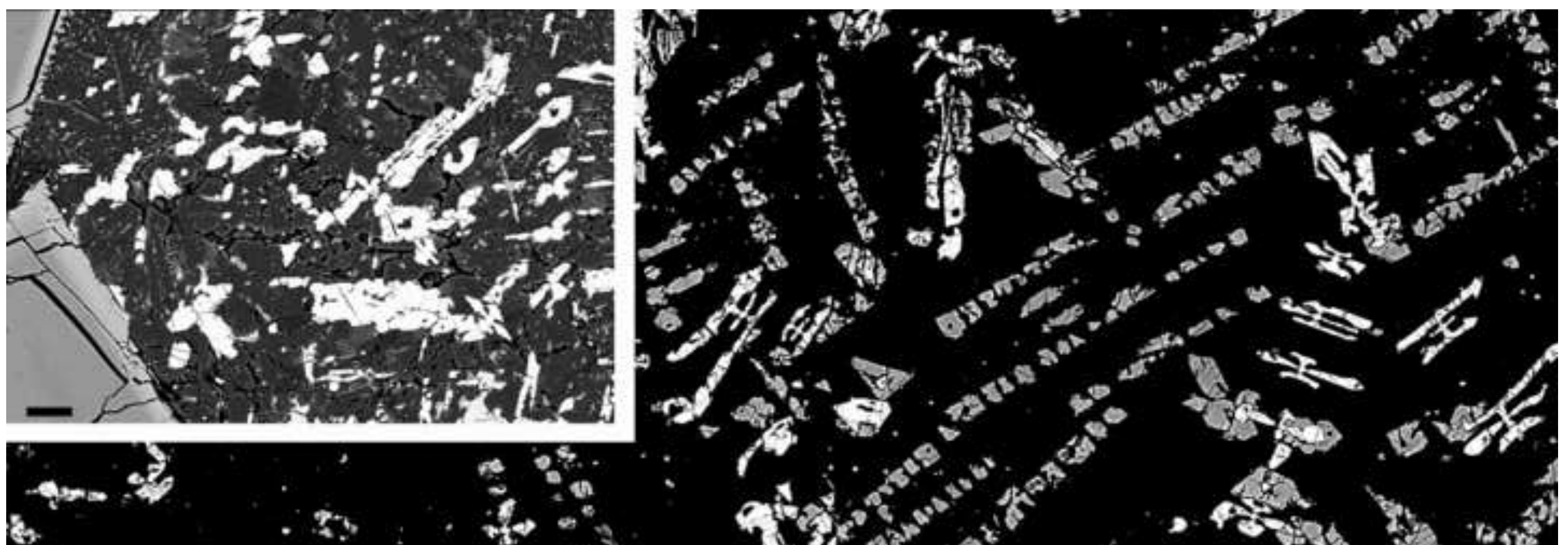

6

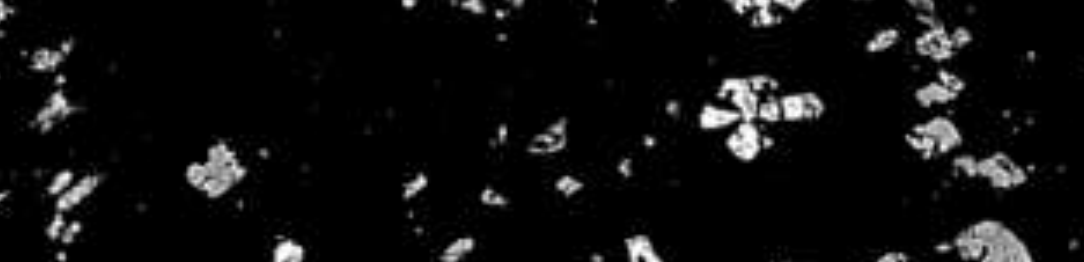

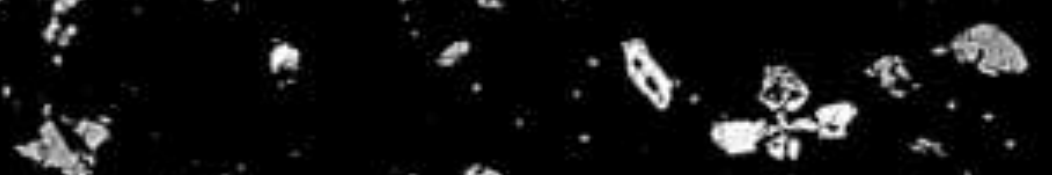

$20 \mu \mathrm{um}$

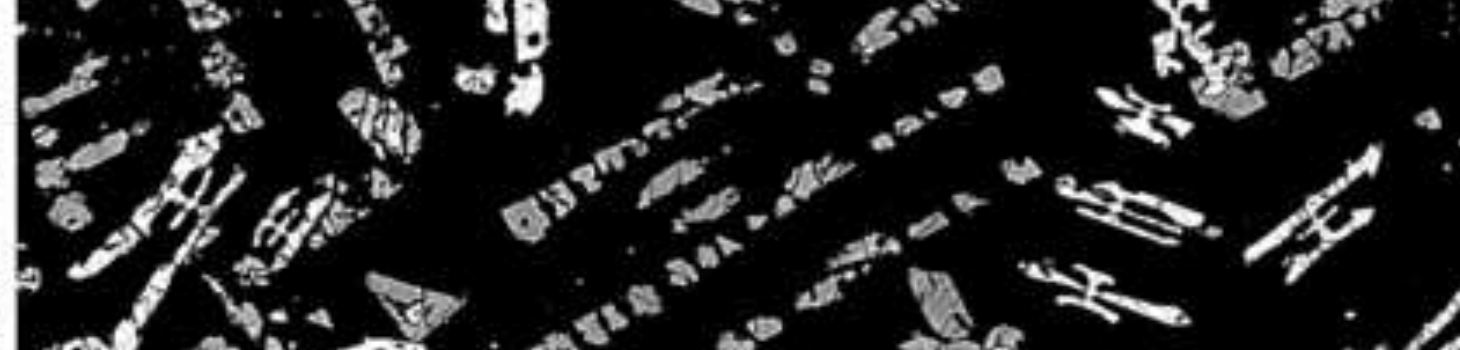

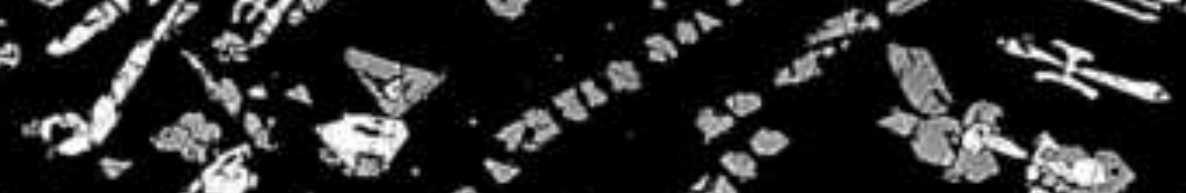
78 क 5

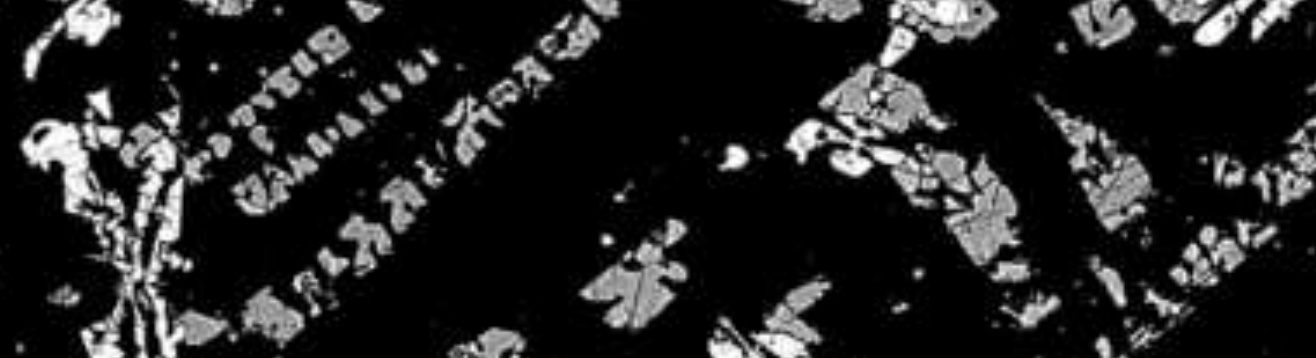
Ab क क स $50.0 \%$

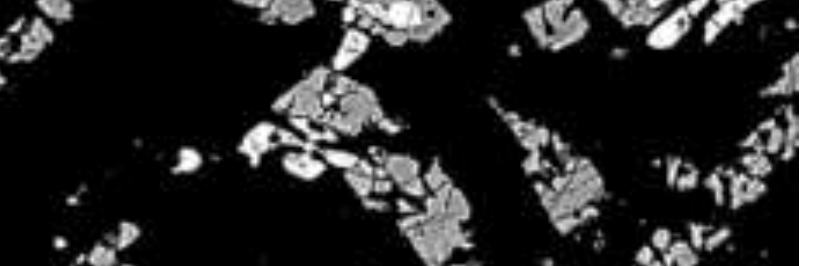
a

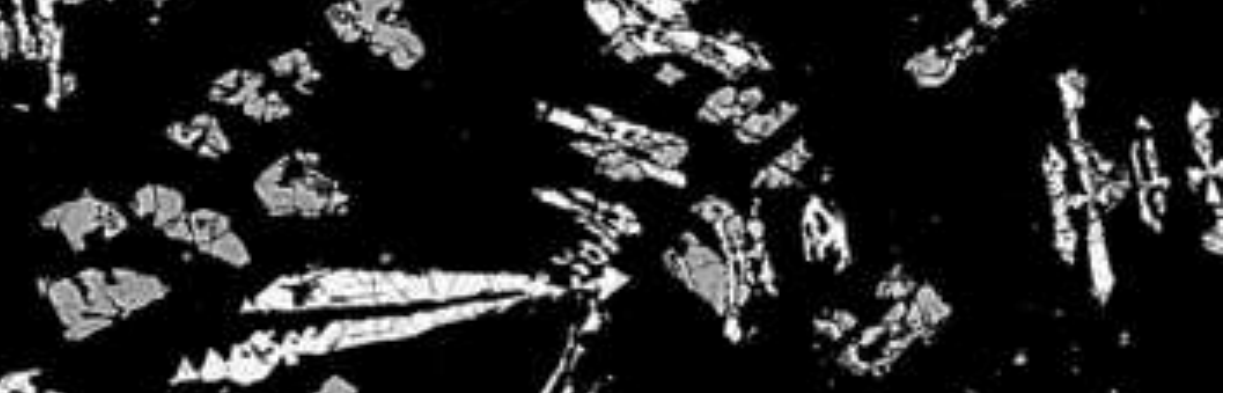
(10 

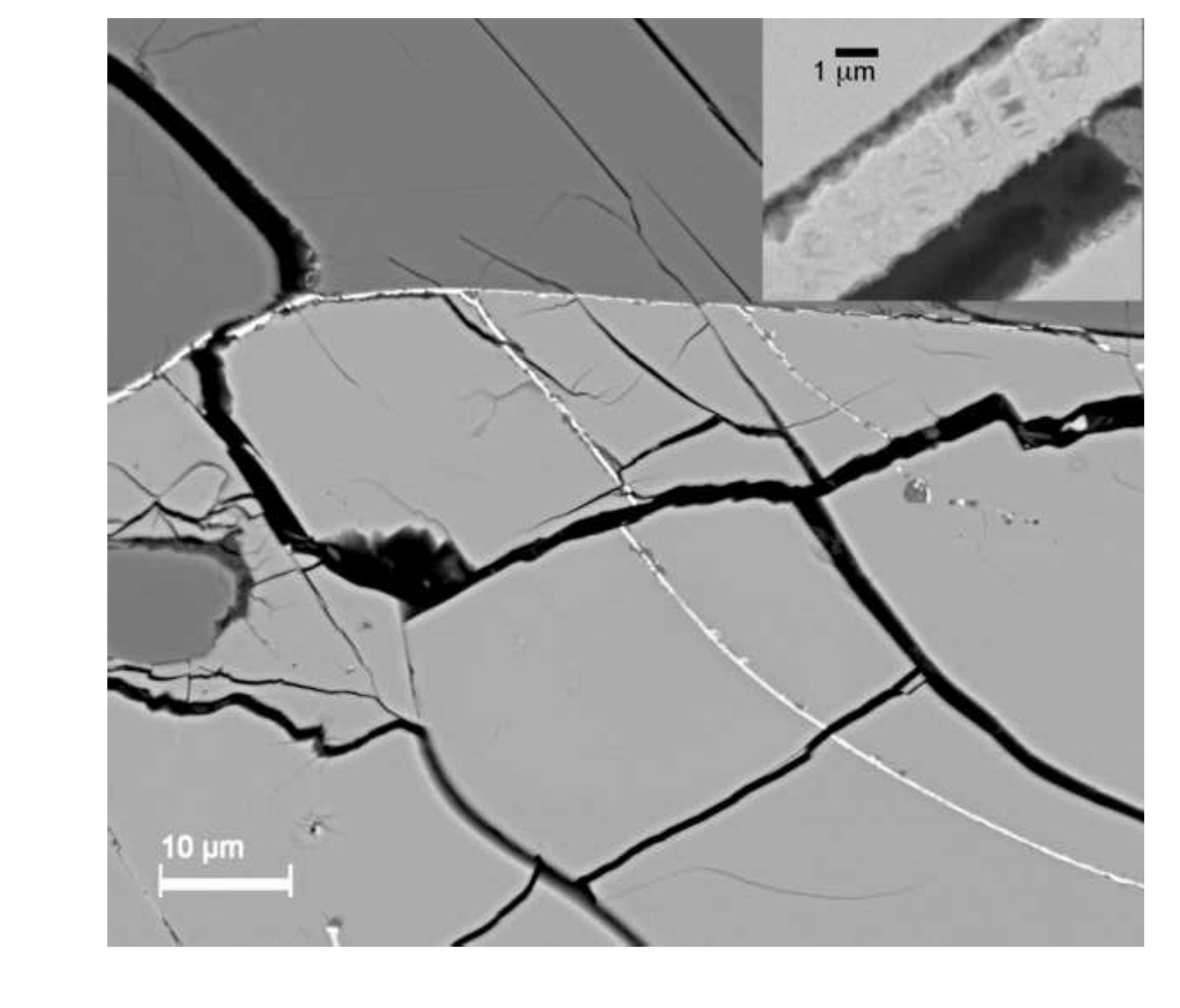
Figure 100
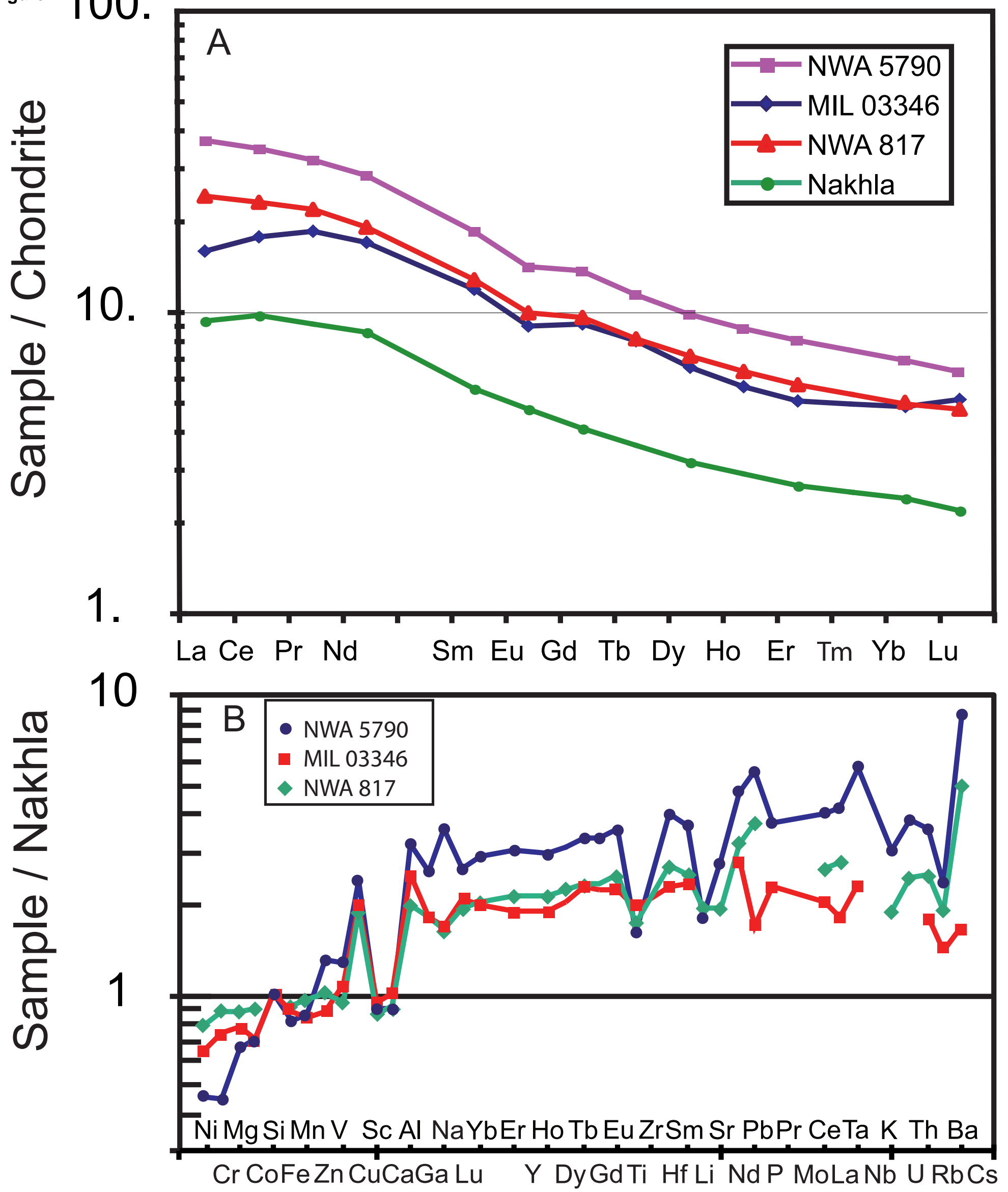

Figure 8 Jambon et al. 
Figure 9

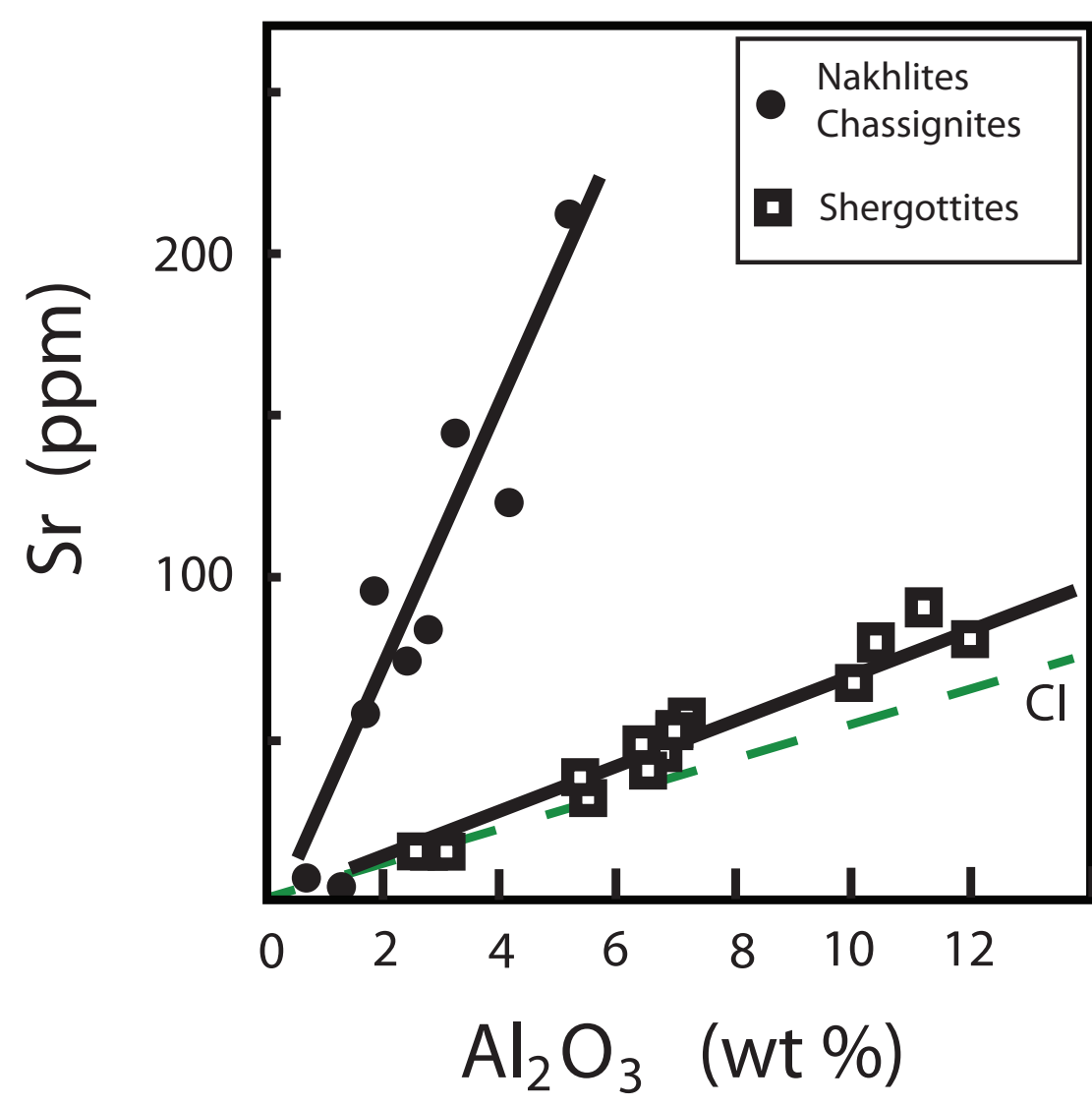

Figure 9. Jambon et al. 


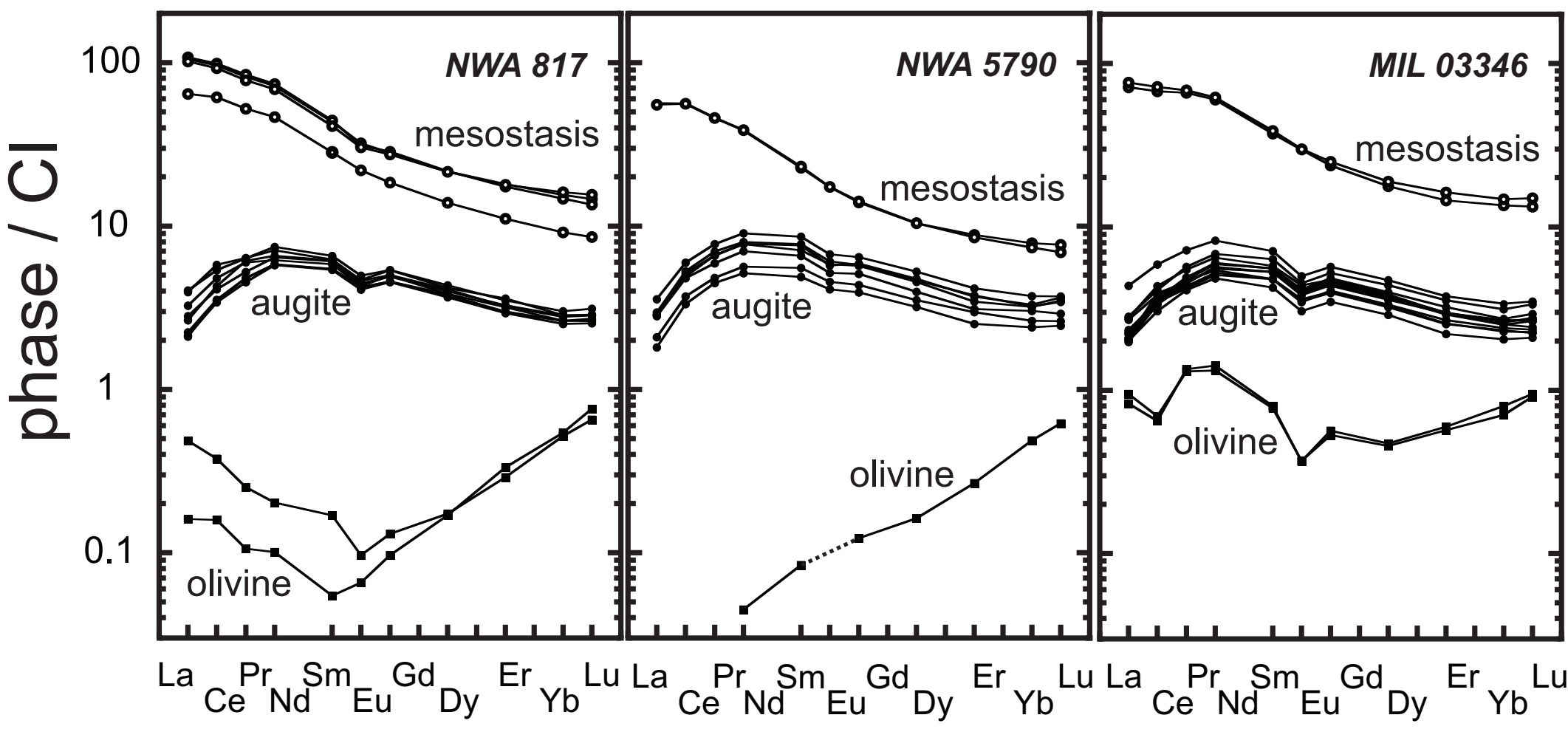

Figure 10: Jambon et al. 


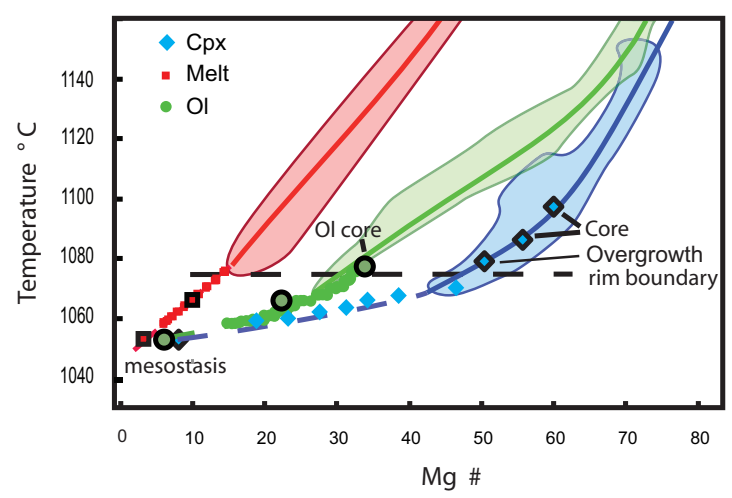

Figure 12. Jambon et al. 


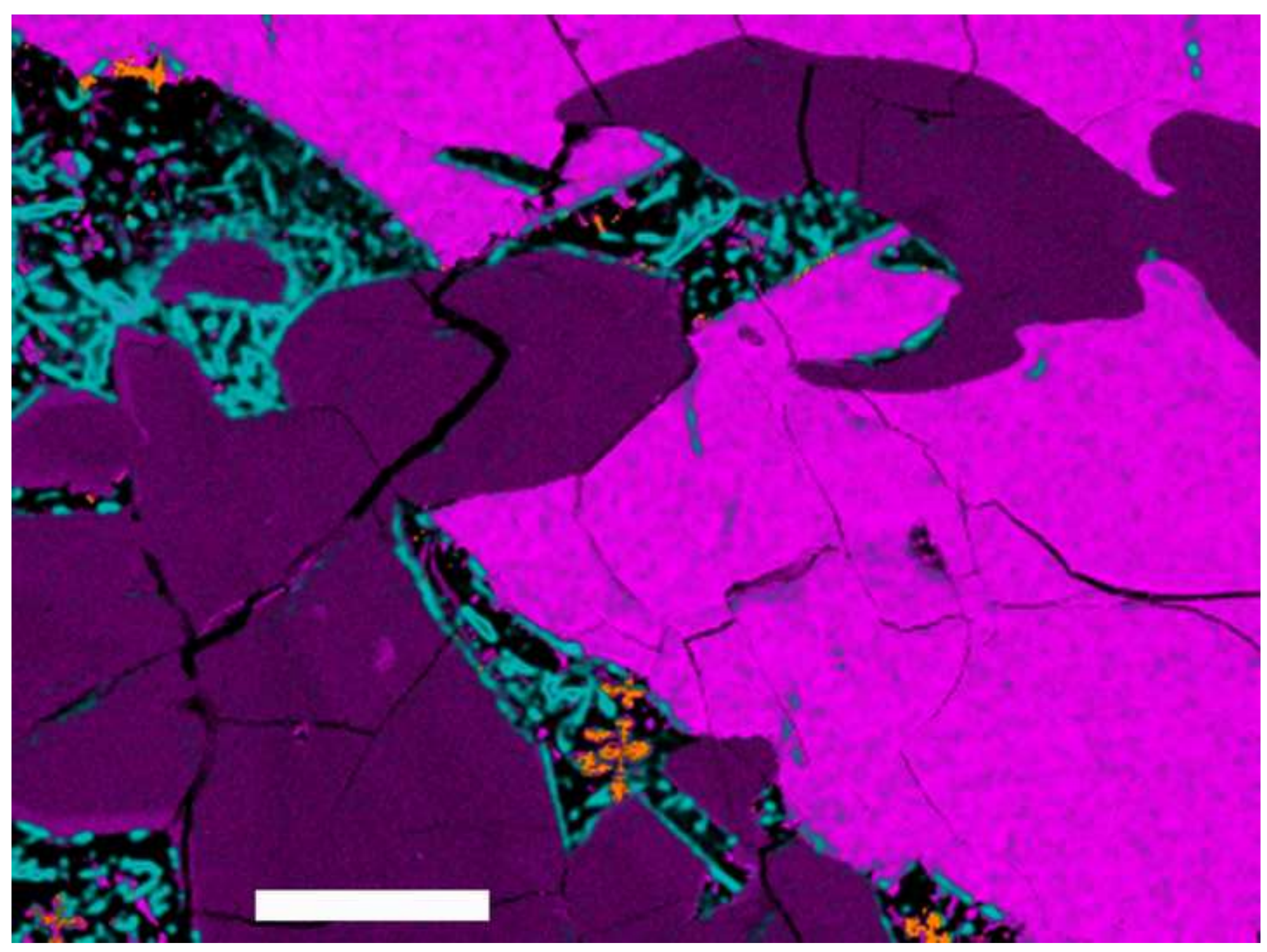




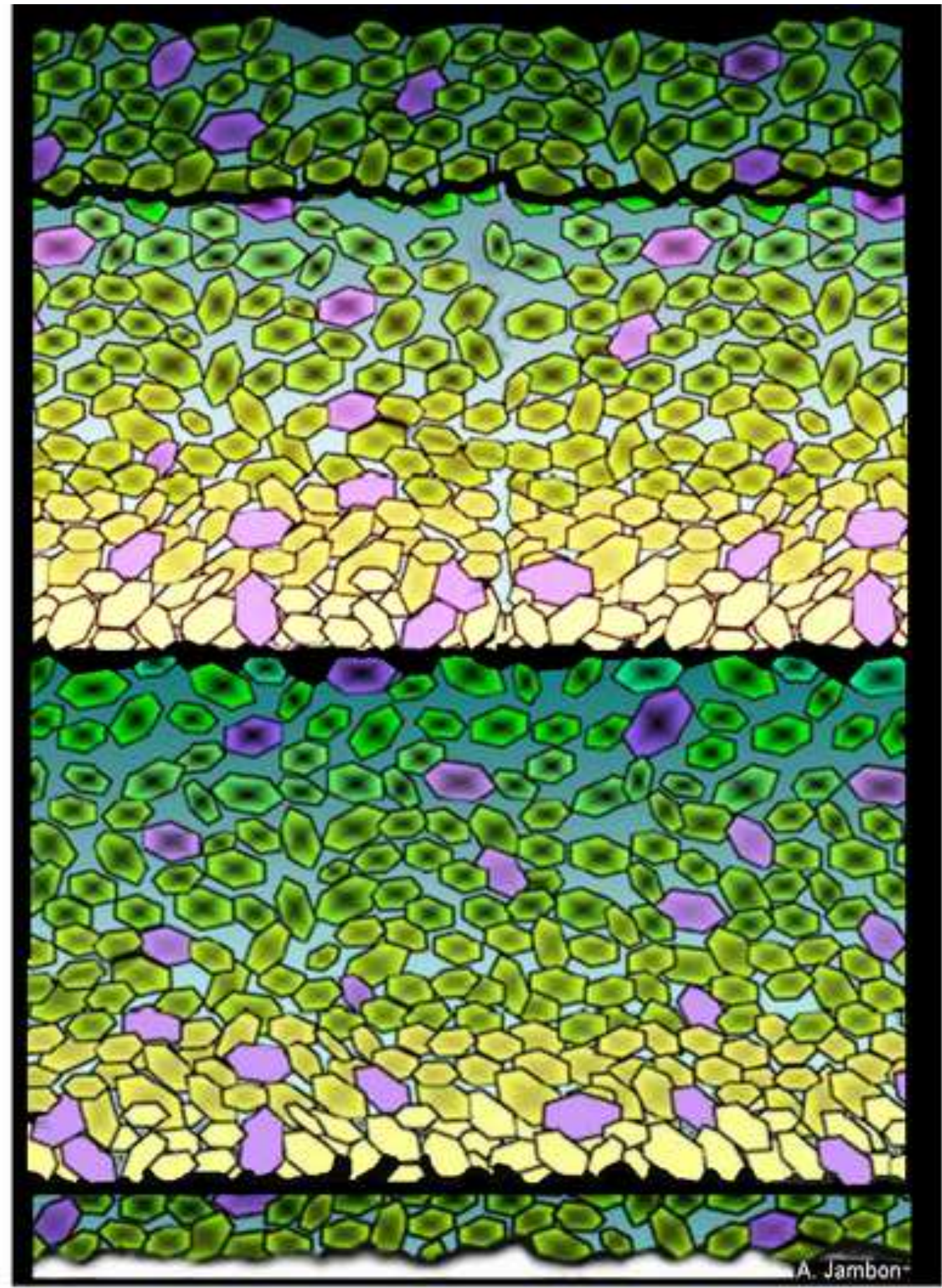

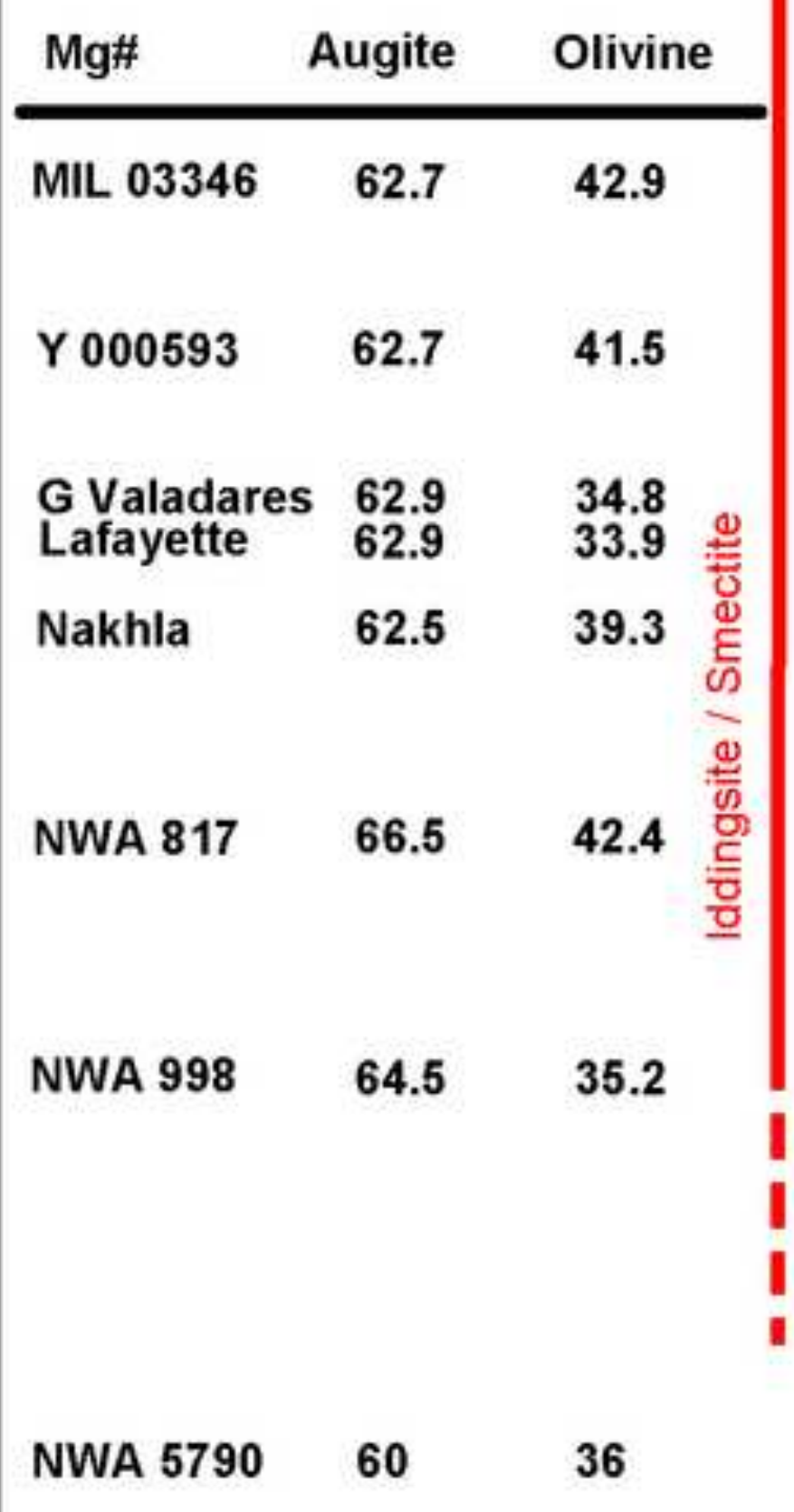

